Ocean Dynamics

September 2016, Volume 66 Issue 9 Pages 1181-1207

http://dx.doi.org/10.1007/s10236-016-0974-7

http://archimer.ifremer.fr/doc/00353/46428/

(c) Springer-Verlag Berlin Heidelberg 2016

\title{
Influence of bottom trawling on sediment resuspension in the 'Grande-Vasière' area (Bay of Biscay, France)
}

\author{
Mengual Baptiste ${ }^{1,{ }^{*}}$, Cayocca Florence ${ }^{1}$, Le Hir Pierre ${ }^{1}$, Draye Robin ${ }^{2}$, Laffargue Pascal ${ }^{2}$, \\ Vincent Benoit ${ }^{3}$, Garlan Thierry ${ }^{4}$
}

${ }^{1}$ IFREMER DYNECO DHYSED, Ctr Bretagne, ZI Pointe Diable, CS 10070, F-29280 Plouzane, France.

2 IFREMER EMH, Ctr Atlantique, Rue Ile Yeu,BP 21105, F-44311 Nantes 03, France.

${ }^{3}$ IFREMER STH LTBH, Stn Lorient, 8 Rue Francois Toullec, F-56100 Lorient, France.

${ }^{4}$ SHOM DOPS HOM Sedimentol, 13 Rue Chatellier, CS 92803, F-29228 Brest 02, France.

* Corresponding author : Baptiste Mengual, email address : baptiste.mengual@ifremer.fr

\begin{abstract}
:
Sea trials were performed on two zones with different fishing efforts on the continental shelf of the Bay of Biscay ('Grande-VasiSre' area of muddy sand) in order to assess particulate matter resuspension and seabed disturbances (i.e., penetration, reworking, grain size changes) induced by different types of trawls. Optical and acoustic measurements made in the water column indicate a significant trawlinginduced resuspension mainly due to the scraping action of doors. It manifests as a highly dynamic turbid plume confined near the seabed, where suspended sediment concentrations can reach $200 \mathrm{mg} \mathrm{l(-1)}$. Concentration levels measured behind an "alternative" configuration (trawls with jumper doors instead of classical doors penetrating the sediment) are significantly lower (around 10-20 mg I(-1)), which indicates a potential limiting impact regarding the seabed. Grain size analyses of the surficial sediment led to highlight a potential reworking influence of bottom trawling. On the intensively trawled zone, this reworking manifests as an upward coarsening trend in the first $5 \mathrm{~cm}$ of the cores. A significant decrease in mud content (30\%) has been also witnessed on this zone between 1967 and 2014, which suggests an influence on the seabed evolution. The geometric analysis of bottom tracks (4-5-cm depth, $20-\mathrm{cm}$ width) observed with a benthic video sledge was used to compute an experimental trawling-induced erosion rate of $0.13 \mathrm{~kg} \mathrm{~m}(-2)$. This erosion rate was combined with fishing effort data, in order to estimate trawling-induced erosion fluxes which were then compared to natural erosion fluxes over the Grande-VasiSre at monthly, seasonal and annual scales. Winter storms control the annual resuspended load and trawling contribution to annual resuspension is in the order of $1 \%$. However, results show that trawling resuspension can become dominant during the fishing high season (i.e., until several times the natural one in summer). In addition, the contribution of trawling-induced resuspension is shown to increase with water depth, because of the rapid decay of wave effects. Finally, the seasonal evolution of the respective contributions for erosion (mainly trawling and waves) could be mapped for the whole study area.
\end{abstract}

Keywords : Bottom trawling, Sediment resuspension, Seabed disturbance, Erosion flux, Bay of Biscay 
Environmental issues linked to bottom trawling have been studied for several decades in terms of seabed alteration, benthic ecosystem disturbances, and fish stocks overexploitation (e.g. Graham 1955; Main and Sangster 1979, 1981, 1983; De Groot 1984; Kaiser et al. 2002). The development of more 
efficient and impacting fishing techniques starting in the sixties raised the international awareness of the environmental issue associated with their use (Cole 1971; Van Beek et al. 1990). The use of heavier gears (Cole 1971; Chittenden and Van Engel 1972; Linnane et al. 2000) indeed improved their efficiency, while increasing their impact on the seabed and benthic ecosystems (Jones 1992; Hall 1999). Nowadays, physical and biological impacts induced by bottom trawling are qualitatively known (e.g. reviews: Jones 1992; Linnane et al. 2000; Kaiser et al. 2002; Martín et al. 2014) and most authors agree to state that trawling probably constitutes the main anthropogenic pressure on the continental shelves and slopes worldwide (Watling and Norse 1998; Puig et al. 2012).

Trawling-induced seabed scraping is responsible for the injection of sediments in the water column, that results in a local turbidity increase (up to several hundreds of mg. ${ }^{-1}$ ) and the formation of a turbid plume in the trawl wake (e.g. Schubel et al. 1979; Schoellhamer 1996; Durrieu de Madron et al. 2005; Dellapenna et al. 2006). The plume characteristics (i.e. lateral and horizontal extensions, suspended sediment concentrations, duration) depend on multiple factors such as seabed composition (fine particles content), trawl type and traction speed, and local hydrodynamic forcing (Linnane et al. 2000; O'Neill and Summerbell 2011). The turbid plume height usually reaches 2 to 3 times the net vertical opening (Main and Sangster 1981; Durrieu de Madron et al. 2005) and its lateral spreading generally ranges from a few tens to several hundreds of meters depending on the distance from the source. For instance, in the case of muddy seabeds in the micro-tidal environment of the Gulf of Lions (Mediterranean sea), Durrieu de Madron et al. (2005) measured a $5 \mathrm{~m}$ high and $150 \mathrm{~m}$ wide turbid plume at $90 \mathrm{~m}$ water depth. The turbid plume lifetime mainly depends on the settling velocity and the concentration of the particles in suspension (which have an impact on flocculation processes), the current velocity (responsible for advection), and turbulent shear in the bottom boundary layer (Manning and Dyer 1999; Durrieu de Madron et al. 2005; O'Neill and Summerbell 2011). For instance, Durrieu de Madron et al. (2005) observed that 30 minutes after its generation, the suspended sediment load had reduced from one to two thirds of its value just after trawling, and less than one third remained in suspension after a few hours. In certain environments, sediments resuspended by trawling may contribute to the maintenance of the bottom nepheloid layer (Schoellhamer 1996; Pilskaln et al. 1998; Palanques et al. 2001). While inducing sediment resuspension, trawls are likely to initiate the release of nutrients or contaminants and more generally to affect chemical exchanges at the water-sediment interface (Olsen et al. 1982; Pilskaln et al. 1998; Bradshaw et al. 2012).

At the continental shelves scale, some areas may be trawled several times per year (e.g. Churchill 1989; Oberle et al. 2015a). Several estimates of the annual area trawled on the continental shelves worldwide have been proposed in previous studies. For instance, Watling and Norse (1998), Kaiser et al. (2002), or more recently Oberle et al. (2015a) respectively estimated a total area of 14.80, 19.98, and 13.67 million $\mathrm{km}^{2}$ trawled per year. Combining these values with existing estimates of local trawling-induced sediment resuspension fluxes (Churchill 1989; Durrieu de Madron et al. 2005; Dellapenna et al. 2006; Dounas et al. 2007; O'Neill and Summerbell 2011), Oberle et al. (2015a) estimated a global bottom trawling-induced resuspension of $21.87 \mathrm{Gt}_{\mathrm{yr}} \mathrm{yr}^{-1}$ which is on the same order of magnitude as the annual fluvial sediment flux to the ocean (17.8-20 $\mathrm{Gt}^{-y^{-1}}$, according to Syvitski et al. 2005).

Churchill (1989) showed that when wave action is weak, trawling could be the most significant source of resuspension on the outer shelf of the Middle Atlantic Bight. Furthermore, resuspended sediments are potentially advected away from the generation source. For instance, Ferré et al. (2008) estimated that trawling activities in the Gulf of Lions could contribute up to $20 \%$ of the annual shelf-to-slope export of suspended sediment at the scale of the Gulf. On the NW Iberian shelf, Oberle et al. (2015a) estimated that $65 \%$ of resuspended sediment by bottom trawling $\left(8.78 \mathrm{Mt}^{-y^{-1}}\right)$ were exported offshelf, which represented a six-fold increase regarding natural off-shelf sediment transport. More generally, trawling-induced resuspension becomes more and more significant over natural resuspension as the water depth increases and as the wave contribution to the total bottom shear stresses decreases (e.g. Oberle et al. 2015a).

Fishing gears leave marks on the seabed; the characteristics of these tracks (penetration depths, longevity) depend on the sediment fine particles content, the type of trawl gears and the magnitude of local natural forcing. In sandy environments exposed to waves and currents, shallow tracks (a few centimetres) can be filled within a few hours (Krost et al. 1989). Tracks depth may be more significant 
in muddy sediments (up to $30 \mathrm{~cm}$ deep) and last up to several months or even a few years in deeper environments (beyond 50 meters water depth, e.g. Jones 1992; Linnane et al. 2000; Palanques et al. 2001; Gilkinson et al. 2015). Puig et al. (2012) nicely showed how repeated ploughing action due to trawling drastically smoothed the submarine canyons topography. The surficial sediment can be deeply disturbed in terms of vertical structure (mixing, lithology; e.g. Mayer et al. 1991; Simpson and Watling 2006; Oberle et al. 2015b), habitat complexity (Schwinghamer et al. 1996), bottom roughness (Jennings et al. 2009), grain size and biogeochemical features (e.g. Pilskaln et al. 1998; Palanques et al. 2001; Brown et al. 2005; Dellapenna et al. 2006; Bradshaw et al. 2012; Oberle et al. 2015b), bioturbation rates linked to floral and faunal communities that are likely to influence the sediment stability (Pilskaln et al. 1998), and even consolidation state (Schoellhamer 1996). However, as reported by Oberle et al. (2015b), although trawling-induced effects on benthic organisms and sediment biogeochemistry (e.g. Bradshaw et al. 2012; Pusceddu et al. 2014) are well documented, the trawling-induced seabed changes in terms of sediment texture and lithology remain poorly understood.

The large impact of trawling on natural sediment and associated habitats induced a recent awareness of the need to develop new less-impacting trawling techniques. In particular, attempts for reducing the penetration in sediment lead to new gears the impact of which have to be investigated. Designing alternative gears less damaging regarding the marine environment is becoming a new technological challenge.

This study aims to quantify the weight of trawling activity among factors of resuspension on the continental shelf, considering i) the type of gear (more or less impacting), ii) the seabed composition (muddy sands with various mud concentrations) and iii) the fishing effort. The chosen site is the main mud belt on the continental shelf of the Bay of Biscay, called the "Grande-Vasière". We successively assess the trawling-induced resuspension for two types of gears, the potential influence of trawls on sediment sorting (grain size and water content analyses), and the trawl marks characteristics left on the seabed. We propose an original evaluation of a trawling-induced erosion rate based on the image processing of in situ trawling tracks videos. Finally, we assess the natural and the trawling-induced erosion fluxes over the whole study area so as to compare their relative contributions, depending on the water depth and the season.

\section{Environmental setting of the "Grande-Vasière", a large muddy zone in the Bay of Biscay}

\subsection{Description of the environmental setting of the "Grande-Vasière"}

The "Grande-Vasière" (hereinafter GV) stretches from Penmarc'h at the north to the Rochebonne shoal at the south on the French Atlantic continental shelf. Its limits are roughly defined by the contour represented on Fig. 1, with a total surface of about $17500 \mathrm{~km}^{2}$.

The presence of mud in the GV area is thought to result from Holocene deposits still fed by a modern fine sediment supply (Vanney 1977). Rivers feeding the Bay of Biscay deliver about $2.5 \times 10^{6}$ t. $\mathrm{yr}^{-1}$ of fine sediments to the shelf (Jouanneau et al. 1999), with main contributions from the Gironde and the Loire estuaries $\left(1.5 \times 10^{6}\right.$ t.yr $^{-1}$ and $0.5 \times 10^{6}$ t.yr $^{-1}$ respectively, Castaing and Jouanneau 1987). Jouanneau et al. (1999) described the GV as a "mud belt" (McCave (1972) terminology) representing $75 \%$ of the surface covered by muddy sediments on the French Atlantic shelf. However, Dubrulle et al. (2007) described it as a patch of poorly sorted sands with entrapped fine-sediment material. This description is supported by observations showing that fine-sediment content does not exceed $30 \%$, except near the two extremities (near Penmarc'h and Rochebonne Shoal) identified as preferential depocenters of fine sediments. 


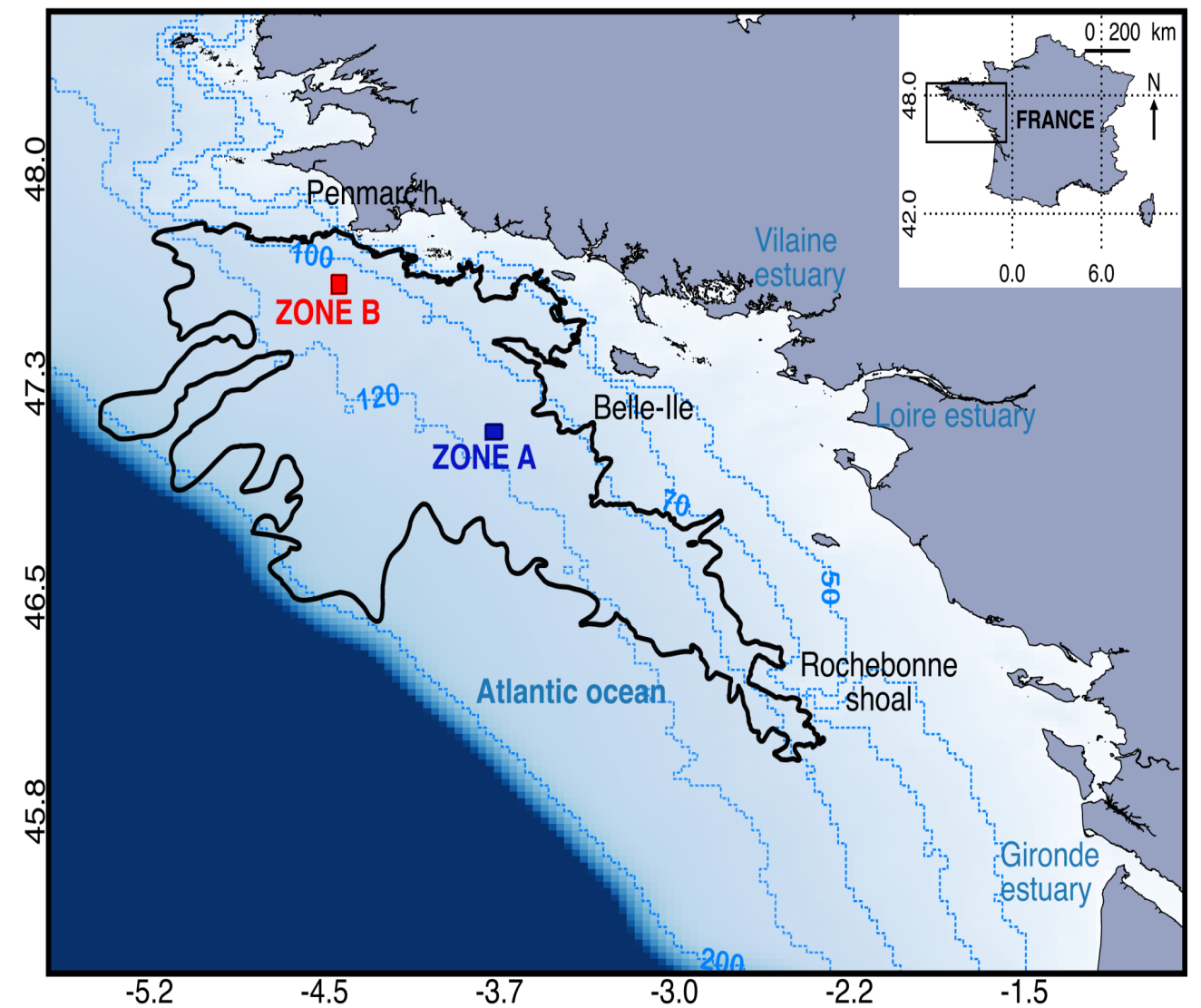

Fig. 1 Map of the study site including the position of zones A and B and the "Grande-Vasière" contour over the northern part of the continental shelf of the Bay of Biscay. Dotted lines in blue represent isobaths. The dark blue shows water depths over the abyssal plain $(>4000 \mathrm{~m})$, and the transition between the dark and light blue shows the continental slope.

Tidal currents on the middle shelf do not exceed $0.15 \mathrm{~m} \cdot \mathrm{s}^{-1}$ (Castaing 1981; Tessier 2006). Between April and September, waves allow very limited sediment resuspension. On the other hand, northwesterly winds can induce the transport of estuarine plumes towards the shelf break (Lazure and Jégou 1998; Castaing et al. 1999), which induces deposition throughout the shelf. The natural resuspension decrease moving offshore enhances deposition as well. The rest of the year, only winter storms can significantly erode the bottom sediment (Castaing 1981; Barthe and Castaing 1989). They locally generate deep furrows (Folliot 2004) and more generally influence the erosion/deposition dynamics. During these energetic conditions, the GV area can be reduced by half (Pinot 1976). Finally, the resulting annual sedimentation rate ranges from 1 to $3 \mathrm{~mm}$ (Dubrulle et al. 2007).

Regarding seabed properties, Dubrulle et al. (2007) measured homogeneous vertical profiles of ${ }^{210} \mathrm{~Pb}$ in the seabed that suggest that the upper 7-20 cm of sediment have been mixed within the last decades. They mentioned bioturbation as one of the potential factor explaining this surficial mixing. In addition, this region is intensively trawled (mainly for Norway lobster), which lead Dubrulle et al. (2007) to suggest fishing activities as an additional source of mixing. From historical grain size data (Vanney 1977; Le Loc'h 2004; Bourillet et al. 2005), Bourillet et al. (2006) showed an increase of the sand/mud (mud: $<63 \mu \mathrm{m}$ ) ratio (from 4 to 6 ) over the past 30 last years corresponding to a fine particle loss. Bourillet et al. (2006) roughly estimated the annual resuspended mass of fine sediments induced by storms (between 850 and $2000 \mathrm{Mt}$ ) and compared it with the one related to bottom trawling based on the combination of fishing efforts data and characteristics of the gears commonly used in the GV (between 180 and $380 \mathrm{Mt}$ ). They concluded that the fine material resuspended by bottom trawling could amount to 10 to $30 \%$ of the quantity mobilized by storms and that trawling could strongly influence the temporal evolution of the seabed in terms of structure and composition. These estimates were based on overly simplifying hypotheses (all detailed in the discussion section 5.4), particularly regarding the quantification of the trawling-induced erosion flux. The penetration 
depth of the various trawling gears had indeed not been quantified for any kind of trawl in the GV, nor had the turbidity generated in the trawl wake been described. Carrying out these quantifications is one of the objectives of the present study detailed in Section 3.

In order to assess the impact of trawling activities on the seabed, two $16 \mathrm{~km}^{2}$ zones undergoing fishing efforts of contrasting magnitudes were selected (A and B, Fig. 1). Both zones exhibit approximately the same water depth $(\sim 110 \mathrm{~m})$. "Zone A", located near Belle-Ile island (central part of the GV), undergoes a moderate fishing activity whereas "Zone B" (northern part of the GV) is intensively trawled. The same experiments were carried out in both areas, and are reported in Section 3.

A first series of investigation based on sediment sampling consisted in examining the surficial sediment characteristics for both zones. Measurements aimed to investigate differences between the two zones as well as the potential signature of the bottom trawling influence in the surficial sediment properties (i.e. grain size vertical profiles, fine fraction evolution over time).

\subsection{Core analyses (grain size vertical profiles)}

Surface sediment cores were sampled with a multiple corer preserving the interface (from Bowers and Connelly) using Perspex cores (internal diameter: $10 \mathrm{~cm}$, length: $50 \mathrm{~cm}$ ). Sediment cores were cut in 1 $\mathrm{cm}$ thick layers, every centimetre for the five upper centimetres, and then every $5 \mathrm{~cm}$ down to $25 \mathrm{~cm}$ below the interface. Grain size analysis and water content were carried out over the upper $25 \mathrm{~cm}$ of the cores sampled in the two zones during the May and June 2014 cruises ( 8 cores were sampled on zone A, 12 cores on zone B).
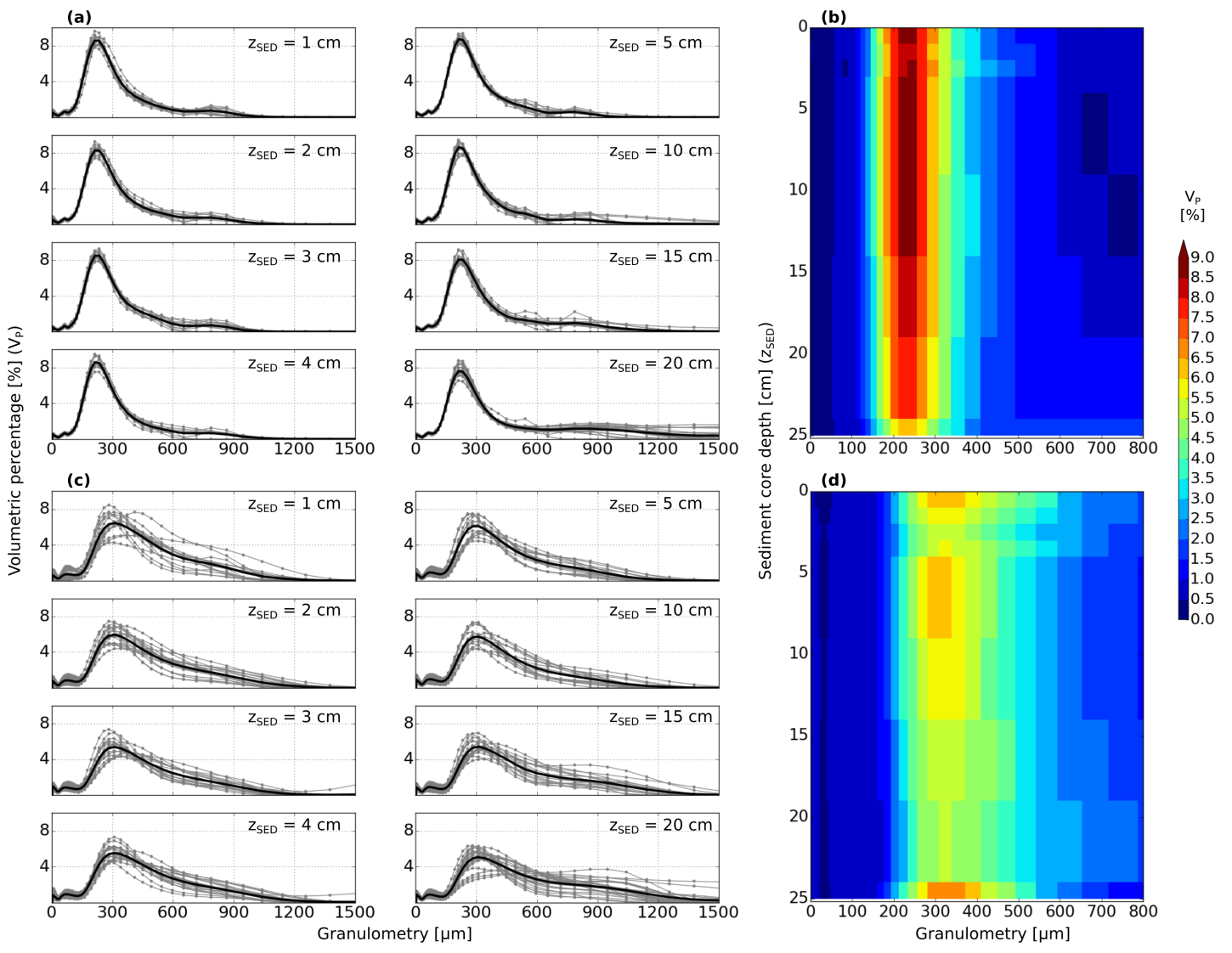

Fig. 2 Grain size spectra (in volumetric percentage $V_{P}$ ) of all cores at each sediment core depth ( $z_{S E D}$ ) for zone $A$ (a) and B (c) represented by thin grey curves with the corresponding average grain size spectra represented by thicker black curves. Subplots (b) and (d) provide synthetic visions of grain size spectra over sediment core depth (upper $25 \mathrm{~cm}$ ) for zone A and B respectively, from individual average grain size spectra (black curves) illustrated at each sediment core depth on subplots (a) and (c). 
Figures $2 \mathrm{a}$ and $2 \mathrm{c}$ illustrate all grain size spectra compiled at each core depth (i.e. $\mathrm{z}_{\mathrm{SED}}=1,2,3,4,5$, 10,15 , and $20 \mathrm{~cm}$ ) for zones $\mathrm{A}$ and $\mathrm{B}$ respectively. It is important to mention that only a few cores enabled to sample sediment until $25 \mathrm{~cm}$ depth. Therefore, average representativeness at this sediment depth can be potentially less significant. In the same way, average vertical profiles of $d_{10}, d_{50}$, mud (< $63 \mu \mathrm{m})$ content, and clay $(<4 \mu \mathrm{m})$ content (hereinafter called "grain size related parameters") were computed from grain size spectra of all stations at each sediment depth for both zones A and B (Fig. 3) as well as the corresponding standard deviations (hereinafter called std).
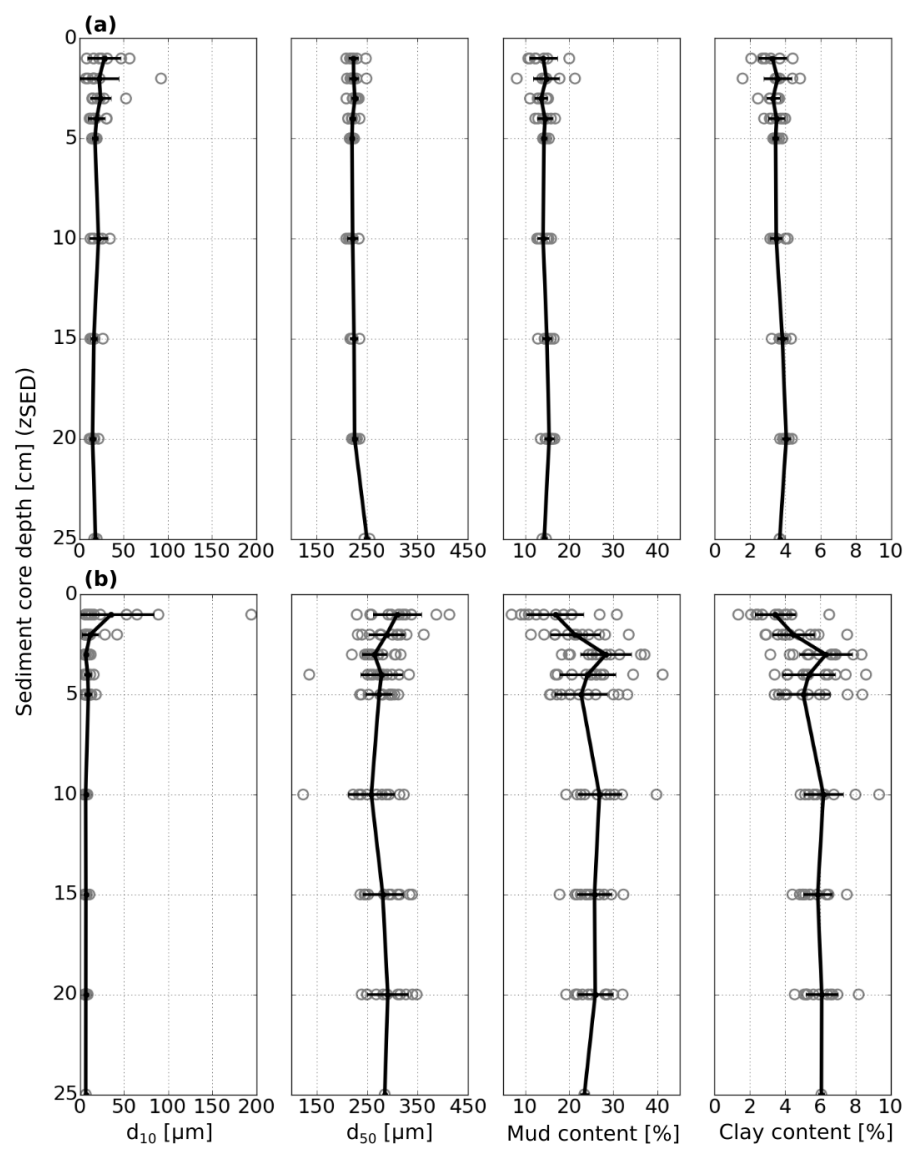

Fig. 3 Averaged vertical profiles of $d_{10}, d_{50}$, mud and clay contents for zone A (a) and zone B (b). Horizontal bars represent the standard deviation at each level, and unfilled grey circles represent individual data of each core at each sediment depth used to compute average and standard deviation values.

In zone A (Fig. 3a), the vertically averaged values for $d_{10}, d_{50}$, mud and clay contents are respectively $20.2 \pm 9.5 \mu \mathrm{m}, 226.3 \pm 7.5 \mu \mathrm{m}, 14.5 \pm 1.6 \%$, and $3.6 \pm 0.4 \%$. Standard deviations of $d_{50}$, mud and clay contents do not exceed $10 \mu \mathrm{m}, 3 \%$, and $0.8 \%$ respectively in the upper $25 \mathrm{~cm}$ of sediment, which shows a certain homogeneity. This homogeneity is particularly visible on Fig. 2a on which average grain size spectra are similar at the different depths within each core and across different stations. Grain size spectra are centred on $d_{50}$, and continuously distributed between 150 and $400 \mu \mathrm{m}$. Nevertheless, std values linked to grain size related parameters seem to increase upwards in the upper 4 centimetres, especially parameters related to $d_{10}$ (from 3.5 to $19 \mu \mathrm{m}$ ), mud content (from 1 to $3 \%$ ) and clay content (from 0.2 to $0.8 \%$ ).

In zone B (Fig. 3b), the vertically averaged values for $d_{10}, d_{50}$, mud and clay contents are respectively $10.7 \pm 7.9 \mu \mathrm{m}, 281.0 \pm 34.1 \mu \mathrm{m}, 23.9 \pm 4.9 \%$, and $5.4 \pm 1.1 \%$. These average $s t d$ values linked to $d_{50}$, mud and clay contents are thus multiplied by a factor $4.5,3.1$ and 2.75 respectively when compared with those obtained for zone A. Generally, std values associated to all grain size related parameters are higher than those obtained for zone A at all sediment core depths and are of the same order of 
magnitude than vertically averaged ones. This variability is visible on Fig. $2 \mathrm{c}$ on which more significant differences in grain size spectra can be noticed between the different stations at all sediment core depths. However, average grain size spectra performed at each sediment depth exhibit similarities regarding their distributions. The mean level grain size spectra are more widely spread and all levels include 2.5 times more coarse particles (above $500 \mu \mathrm{m}$ ) in zone B $(18.8 \pm 2.2 \%$ ) than in zone A $(7.4 \pm 2.1 \%)$. Moreover, the upper 3 centimetres of the sedimentary column exhibit a $d_{10}$ increase (form 6.4 to $35.2 \mu \mathrm{m}$; i.e. $+450 \%$ ) and a $d_{50}$ increase (from 264 to $309 \mu \mathrm{m}$; i.e. $+17 \%$ ) upwards, along with an upward decrease of the mud content (from 28.3 to $16.8 \%$; i.e. $-41 \%$ ) and the clay content (6.3 to $3.4 \%$; i.e. $-46 \%)$.

\subsection{Sonar surveys and temporal evolution of fine fraction in the seabed}

The first step of the experiment was to carry out side scan sonar surveys of each zone (Fig. 4) so as to investigate the homogeneity of the surficial sediment cover. Trawl tracks are visible in both areas and their density seems to be larger on zone B, which is coherent with the fact that it is more intensively trawled (see further, section 4.2.1).
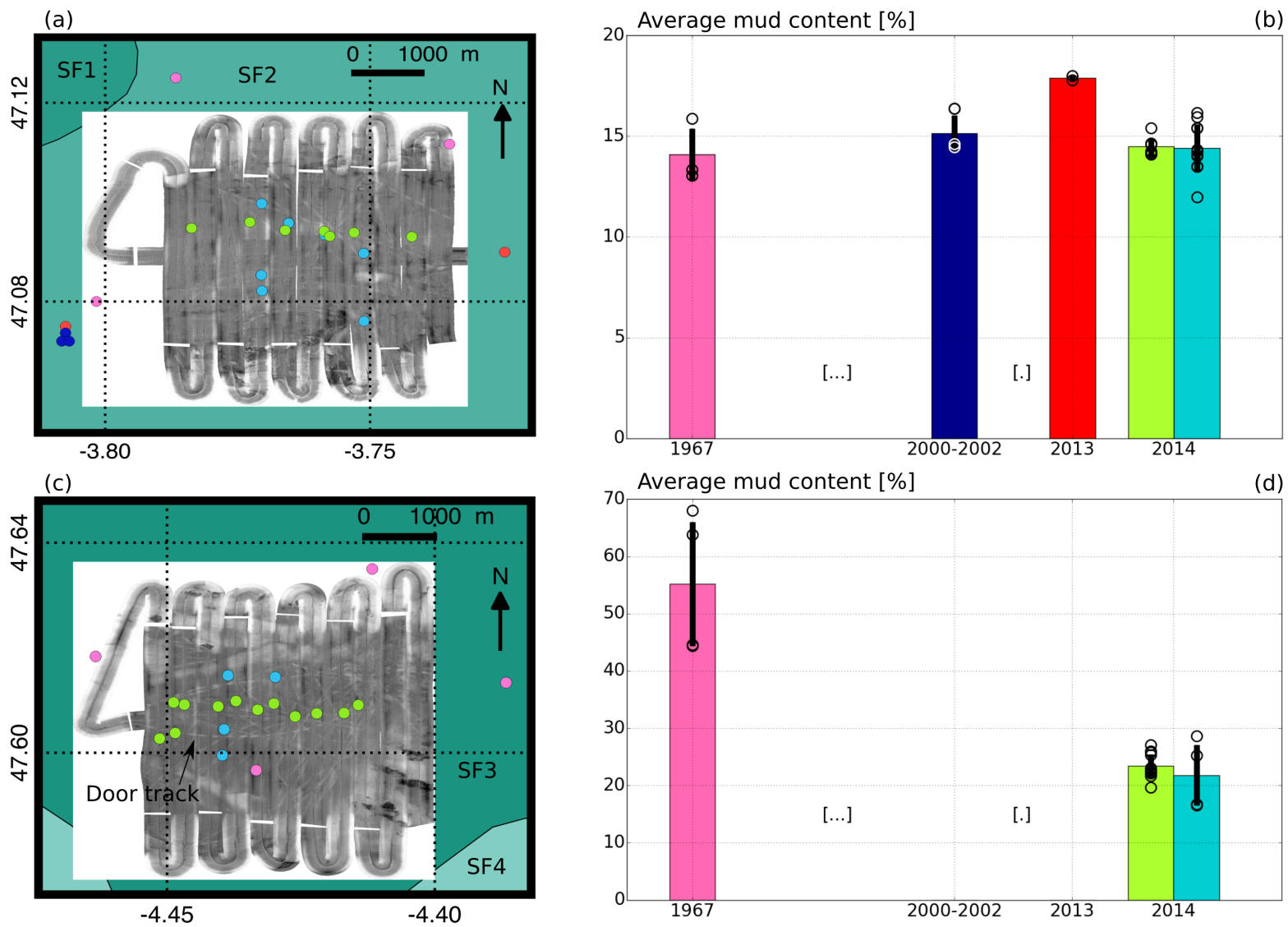

Fig. 4 Side scan sonar maps and historical mud content data localisation for zone A (a) and zone B (c) with the associated average values (over the upper $15 \mathrm{~cm}$ of sediment) at different periods of time (different colours depict different years or periods) on subplots (b) and (d) respectively. For each of these periods and for each zone, unfilled circles on subplots (b) and (d) correspond to mud content data used to compute average mud content values and vertical black error bars correspond to the standard deviations linked to the different periods on each zone. Sonar maps are superimposed to the map of Sedimentary Facies (SF) described by Bouysse et al. (1986) [SF1 (VL2a in Bouysse et al. 1986): Muddy litho-bioclastic sand, SF2 (resp. VL1a): Muddy lithoclastic sand slightly carbonated, SF3 (resp. VL2b): Sandy marl (coarse or gravelly with shells), SF4 (resp. VBb): Sandy calcareous mud (gravelly with shells)]. These facies are visible around sonar images. 
Changes in the GV seabed coverage over the past few decades (past 30 years) have been mentioned in the literature (Bourillet et al. 2006; Dubrulle et al. 2007). In order to confirm this trend and compare historical to modern seabed coverage, historical mud content data from areas surrounding zone $\mathrm{A}$ and zone B were gathered. Historical data points outside of zones A and B (Fig. 4) were included in the analysis, provided they belonged to the same sediment facies SF2 (resp. SF3) as zone A (resp. B), as described in the surficial sediment map from Bouysse et al. (1986). All data acquired before 2014 were collected using Hamon day-grabs (Brown et al. 2002), leading to some sediment mixing over the upper $15 \mathrm{~cm}$. In order to ensure consistency between older and more recent data, mud content values deduced from more recent sediment cores (described in section 2.2) were vertically averaged over the upper $15 \mathrm{~cm}$ of surficial sediment.

Fig. 4 shows the data points location on zones A and B respectively for four different periods when data were available (i.e. 1967, 2000-2002, 2013, and 2014), with the corresponding mud contents averaged over each period. In zone A (Figs. $4 \mathrm{a}, \mathrm{b}$ ), the past 50 years do not exhibit any significant change in mud content with values ranging from 12 to $18 \%$ and standard deviations between $\pm 0.43 \%$ and $\pm 1.28 \%$. On the contrary, zone B (Figs. 4c,d) shows differences of about $30 \%$ in terms of mud content between 1967 and 2014. The average mud content was indeed around 55 $\pm 11 \%$ in 1967 whereas it was only $23 \pm 3.3 \%$ in 2014 .

\subsection{Analysis of the surficial sediment variability in the GV}

The relative homogeneity observed in the vertical profiles of the grain size parameters, especially in zone A, is in agreement with the regular fine sediment supply to the area (Jouanneau et al. 1999). It may be reinforced by the important mixing induced by bioturbation (Le Loc'h 2004). A possible correlation between the benthic fauna density, the bioturbation intensity and the strength of fishing pressure remains an important question not addressed by this manuscript.

The fine fraction decrease over time observed on the intensively trawled zone (B) cannot be explained by changes in the hydrodynamic regime, because i) no tendency of the wave regime in the Bay of Biscay has been described during this period and ii) at the regional scale the two zones are close enough to each other, so that any hydrodynamic trend observed in one zone would be expected in the other one. Regarding river discharges, the main sources of sediment input are the Loire and Gironde rivers. Planque et al. (2003) showed that the Loire river discharge did not exhibit any significant trend between 1840 and 2000; it has remained quite stable since 2000. It can therefore be assumed that changes in mud content cannot be explained by a variation in sediment input either. The Gironde river influence may be assumed to be limited given the distance from zones A and B. Otherwise, the influence from the Gironde river should be larger in zone A than in zone B, but no trend has been observed in the former area.

A potential explanation for a change in surficial sediment can be inferred from investigating the evolution of chronic bottom trawling activities in the past few decades: the overall engine power of the French metropolitan fleet (including the French Atlantic one) has considerably increased between the 1960s and the 1990s (Mesnil 2008), which is coherent with the timing of the observed mud content changes. Such a conclusion is confirmed by more significant trends in grain size related parameters observed in sediment cores of the most intensely trawled area (zone B): upward increases of $d_{10}, d_{50}$ and upward decreases of mud and clay contents in the upper 3-4 centimetres of the surficial sediment (see section 2.2). 


\section{Effects of bottom trawling}

A second series of investigations consisted in quantifying the local trawling-induced resuspension in the water column as well as the seabed micro-topography disturbances (i.e. trawl tracks) induced by each of the trawl parts. Dynamic measurements were made from an oceanographic vessel (N/O Thalia) following a professional trawler in operation (F/V Côte d'Ambre) in different configurations (Fig. 5).

\section{$\underline{3.1 \text { Trawl configurations }}$}

Fig. 5 represents a schematic view of an otter trawl in a twin configuration, as used during all sea trials, and lists the different parts of the trawl. The main trawl parts impacting the seabed are doors, groundropes, and chains.

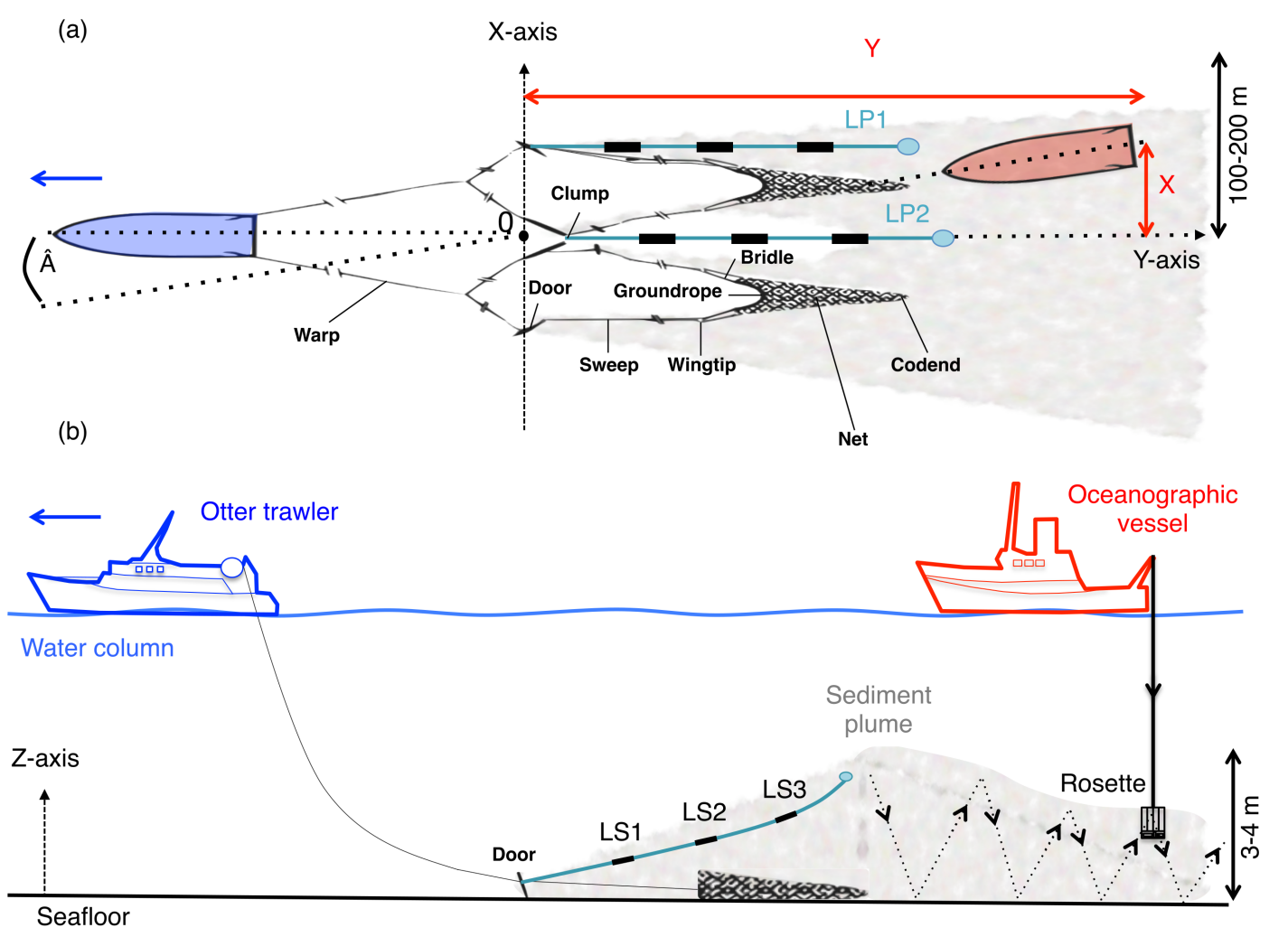

Fig. 5 Schematic view of the trawling gears and representation of the sampling strategy in the (XY) (a) and (YZ) (b) plans (i.e. two dimensions horizontal and vertical respectively) with the different deployments realised to quantify the resuspension induced by the otter twin trawl.

The same otter twin trawl was used during all experiments, under two configurations that only differed by the type of doors. The doors are fixed on both sides of the trawl in order to maintain the lateral opening of the net. Groundropes correspond to an assembly of rubber disks (of identical size in our case), fixed at the basis of the net and thus directly in contact with the seabed. In case of a twin trawl, the clump is the articulation point between the two gears constitutive of the trawl. The trawl characteristics are presented in Table 1. The "classical configuration" uses two Thyboron doors (Fig. 6a), which have a permanent contact with the seabed. An "alternative configuration" uses Jumper doors (Vincent et al. 2015), which have an intermittent contact with the seabed (Fig. 6b). Jumper doors have been developed to limit the contact with the seabed and thus reduce the impacts on the benthic environment as well as the fuel consumption. The door tilts as soon as the shoe (i.e. the door base) collides with the seabed. Its new inclination induces lifting of the door, hence increasing its 
distance from the bed ("jumping" behaviour). The door thus follows the seabed topography while contact with the sea floor is limited. The jumper doors surface and weight are approximately the same as for classical doors. However, the surface in contact with the seabed is significantly reduced in the case of jumper doors, since only the shoe occasionally touches the ground.
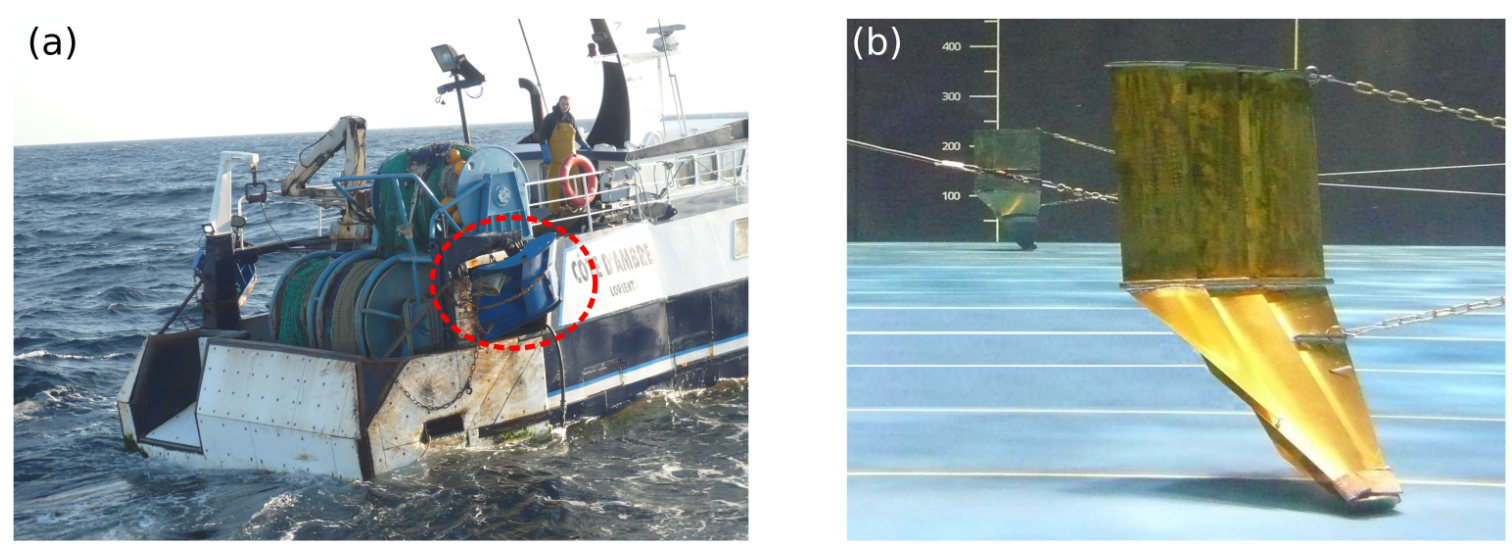

Fig. 6 Illustration of (a) a classical door used during sea trials (circled in red) and (b) Jumper doors during experimental trials [scaled devices, set up in a laboratory flume (Ifremer-Lorient, France)]. Contributors to the creation and development of Jumper door are mentioned in the acknowledgments section.

Table 1 Characteristics of the otter twin trawl used during sea trials

\begin{tabular}{ll}
\hline Device & Characteristics \\
\hline & \\
Trawl type & Otter twin trawl \\
Floatline length & $14 \mathrm{~m}$ for each trawl \\
Sweep length & $50 \mathrm{~m}$ \\
Bridle length & $13 \mathrm{~m}$ \\
Wing spread & $7 \mathrm{~m}$ for each trawl \\
Door spread & $50 \mathrm{~m}$ \\
Vertical opening & $0.8 \mathrm{~m}$ \\
Codend mesh size & $70 \mathrm{~mm}$ (stretched) \\
& \\
Trawler length & $16.5 \mathrm{~m}$ \\
Trawling speed & $3.5 \mathrm{knots}$ \\
& \\
Classical door (Thyboron) & \\
Length & $1.70 \mathrm{~m}$ \\
Weight & $330 \mathrm{~kg}$ \\
Height & $0.95 \mathrm{~m}$ \\
& \\
Groundrope & \\
Length & \\
Weight & $17 \mathrm{~m}$ for each trawl \\
Disk type & $60 \mathrm{~kg}$ for each trawl \\
Disk thickness & Regular \\
Disk diameter & $10 \mathrm{~mm}$ \\
Clump characteristics & $50 \mathrm{~mm}$ \\
Weight & \\
& \\
& \\
& \\
& \\
& \\
& \\
&
\end{tabular}




\subsection{Characterisation of the resuspension plume}

Weather conditions during deployments were calm, with a wind velocity inferior to 10 knots and current velocities that did not exceed $17 \mathrm{~cm} \cdot \mathrm{s}^{-1}$ after integration over a $3 \mathrm{~m}$ high bottom layer. Significant wave height was lower than $1 \mathrm{~m}$ in $100 \mathrm{~m}$ water depth. The ambient turbidity measured in the water column before trawling experiments was vertically homogeneous with values between 2 and $5 \mathrm{mg} . \mathrm{l}^{-1}$ during both cruises. The similar conditions encountered during both deployments make the data sets easily inter-comparable between the two zones.

\subsubsection{Water column measurements}

\subsubsection{Strategy}

The first experiment consisted in assessing the turbid plume generated in the trawl wake with a multisensor probe. The oceanographic vessel stopped as close as possible to the trawl and then progressively got away from it. Up and down movements scanned the water column, avoiding any contact with the seabed, so as to catch the turbid plume signature (Fig. 5b). Measurements of conductivity, temperature, and pressure were acquired with a SeaBird 9/11 CTD probe, while altimetry data were used to control the probe's vertical position above the seabed and thus in the turbid plume. A Sea Tech Optical Backscatterance Sensor (OBS) was mounted on the probe to measure Suspended Sediment Concentrations (SSC), as well as a RDI narrowband $1200 \mathrm{KHz} A D C P$ (Acoustic Doppler Current Profiler) looking downward with four acoustic transducers recording the backscattered acoustic intensity. The return echo was sampled over twenty $25 \mathrm{~cm}$-thick cells. A second experiment aimed at discriminating the impacts of different parts of the gear on trawlinginduced resuspension and at measuring the resuspension as close as possible to the generation location. It consisted in fixing a line equipped with 3 turbidity sensors (WETlabs or NKE types, also monitoring pressure) behind a door (LP1) or behind the clump (LP2, Fig. 5). The sensors were regularly spaced every $20 \mathrm{~m}$ along the line (LS1, LS2 and LS3 respectively at 20,40 and $60 \mathrm{~m}$ from the door or the clump). A buoy was fixed to the upper extremity of the line so as to ensure the appropriate buoyancy allowing the three sensors to be within the wake, at different elevations above the sea floor. In this deployment strategy, the line sensor LS1 was around $0.5 \mathrm{~m}$ above bottom (mab) and the one placed at $60 \mathrm{~m}$ (LS3) was about $2.8 \mathrm{mab}$.

\subsubsection{Processing}

The water column measurements from the multi-sensor probe were replaced in a new mobile coordinate system following the fishing gear, originated in the middle of the segment between the doors and aligned with the direction of both the fishing boat and the otter twin trawl ("Y-axis") (Fig. 5a). The $X$-axis represents the transversal distance from the trawl trajectory. The associated distances $\mathrm{Y}$ and $\mathrm{X}$ describing the instantaneous position of the multi-sensor probe linked to the oceanographic vessel in the trawl wake are expressed with simple trigonometric considerations using the angular difference between the vessels headings $(\hat{\mathrm{A}})$ and the distance between the two vessels, as well as the distance between the trawler and the doors. The vertical Z-axis corresponds to the altimetry above the seabed (Fig. 5b). The data were corrected from bottom current advection by using the ADCP currents integrated over a $3 \mathrm{~m}$ thick layer above the seabed.

Comparing turbidity signals issued from a wide range of instruments requires thorough calibration procedures. Therefore, SSC values from each turbidity sensor were calibrated in the laboratory with suspended sediment samples.

Deriving turbidity estimates from acoustic sensors requires additional processing. As widely described in the literature (e.g. Gartner 2004; Tessier 2006; Tessier et al. 2008b), SSC vertical profiles can be estimated from the backscatter index $B I$ (in decibels, $d B$ ) computed from the ADCP measured back 
scattered intensity, using the sonar equation (Urick 1975; Lurton 2002; see Appendix 1). An empirical relationship is established between $B I$ and the $S S C$ logarithm (e.g. Tessier et al. 2008b) such as:

$\log _{10}(S S C)=c_{1} B I+c_{2}$

In order to compute $c_{1}$ and $c_{2}$, reference $S S C$ values are obtained from simultaneous ADCP and OBS measurements, the latter being calibrated in the laboratory against suspended sediment samples. The OBS is located close to the ADCP transducer head on the multi-sensor probe, while the first ADCP cell is located $0.80 \mathrm{~m}$ below due to the ADCP blanking distance. The calibration was first performed when both instruments were within the turbid plume (all dots on Fig. 7) in order to minimize vertical variability due to turbid fronts. The corresponding coefficients, $c_{1}$ and $c_{2}$ in Eq. (1), are found equal to 0.046 and 3.63 respectively. From this relationship we obtain a coefficient of determination $R^{2}$ of 0.57 and a root mean square error (RMSE) between the OBS and ADCP signals of $26 \mathrm{mg} \cdot \mathrm{l}^{-1}$. Results are however significantly scattered, mainly because $S S C$ gradients can be found within the turbid plumes, especially close to trawling doors, hence partly invalidating the assumed correspondence between OBS and first-cell ADCP records. In order to refine the calibration accuracy, we subsampled the dataset and only used vertically homogeneous ADCP measurements, i.e. profiles for which SSC vertical gradients were lower than $10 \mathrm{mg} \cdot \mathrm{l}^{-1} \cdot \mathrm{m}^{-1}$ and repeated the calibration procedure (clear blue dots on Fig. 7). According to Eq. (1), an optimized linear relation $\left(R^{2}=0.825\right)$ was defined with $c_{1}=0.058$ and $c_{2}=4.131$. This new calibration allows reducing the RMSE between the OBS and ADCP to 4 mg. $1^{-1}$.

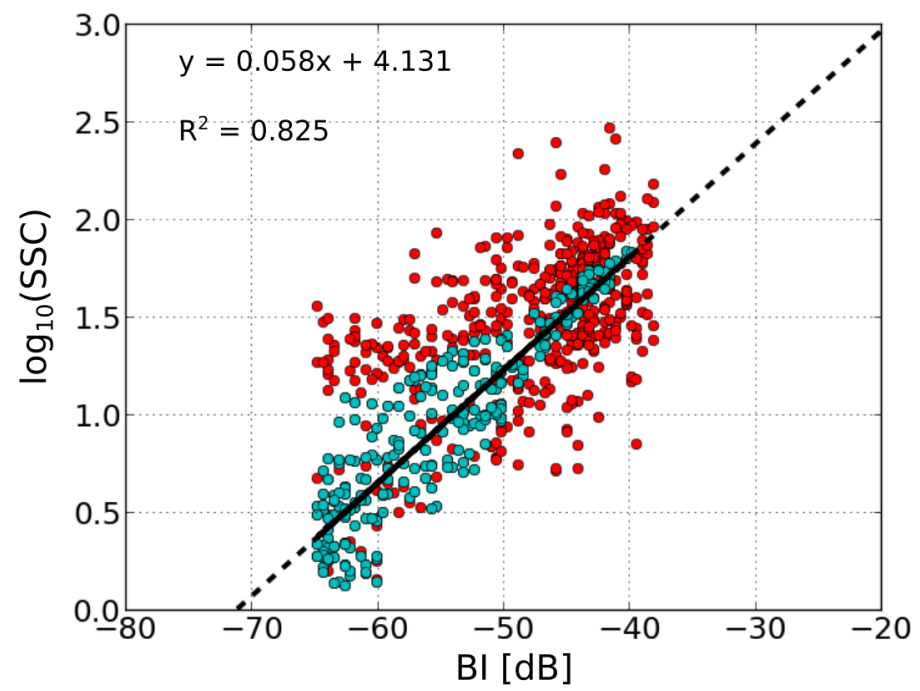

Fig. 7 ADCP calibration: fitting a linear relationship between the backscatter index $B I$ of the first cell of the ADCP and the base-10 logarithm of SSC values measured with OBS sensor on the multi-sensor probe (see text for colour symbols interpretation).

3.2.2 Characterization of suspended sediment concentrations in the trawl wake

\subsubsection{Behind the "classical" configuration of trawl, zone A}

The data obtained during this experiment (about 10 deployments a few minutes long each) are all shown in the new system of coordinates relative to the moving trawler (Fig. 8a).

Assuming the trawling velocity and plume geometry are steady over the sampling time, this choice of reference allows representing a steady picture of the plume features. Following this procedure, Fig. 8a shows a $3 \mathrm{D}$ view of the plume, on which all calibrated SSC values acquired from the OBS sensor and from the ADCP have been compiled. 

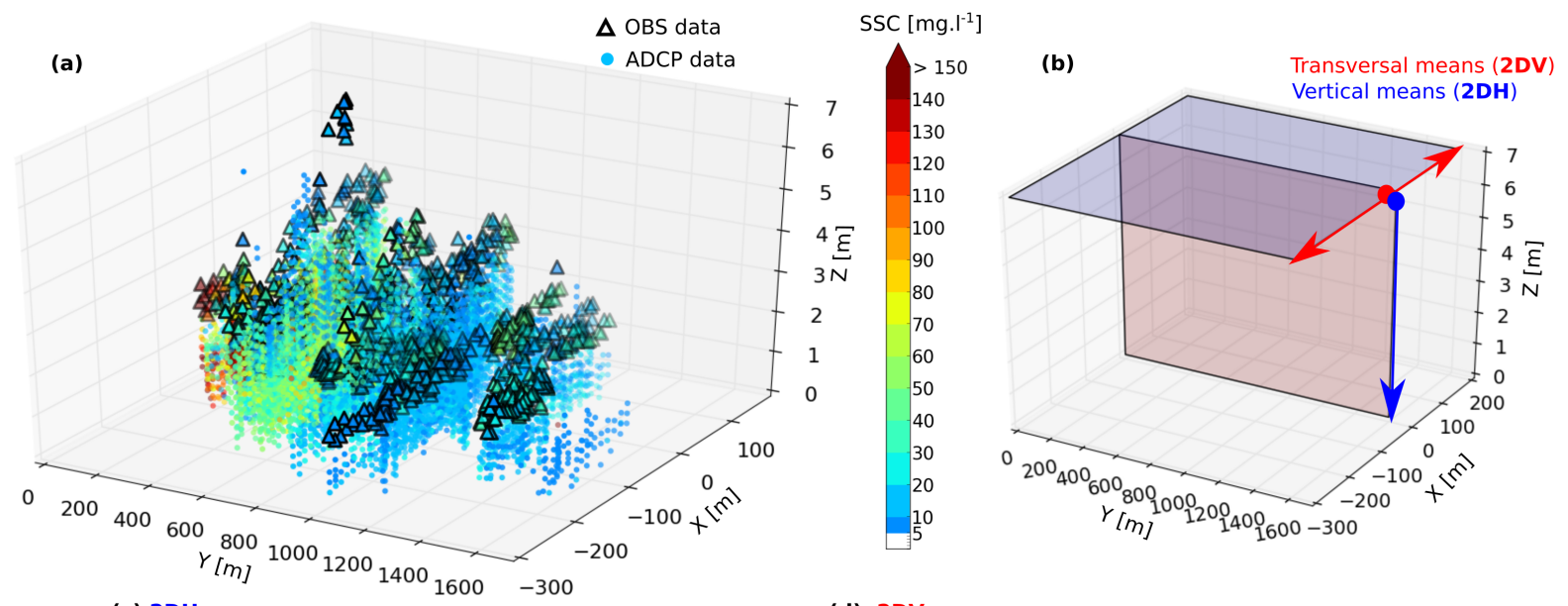

(c) $2 \mathrm{DH}$
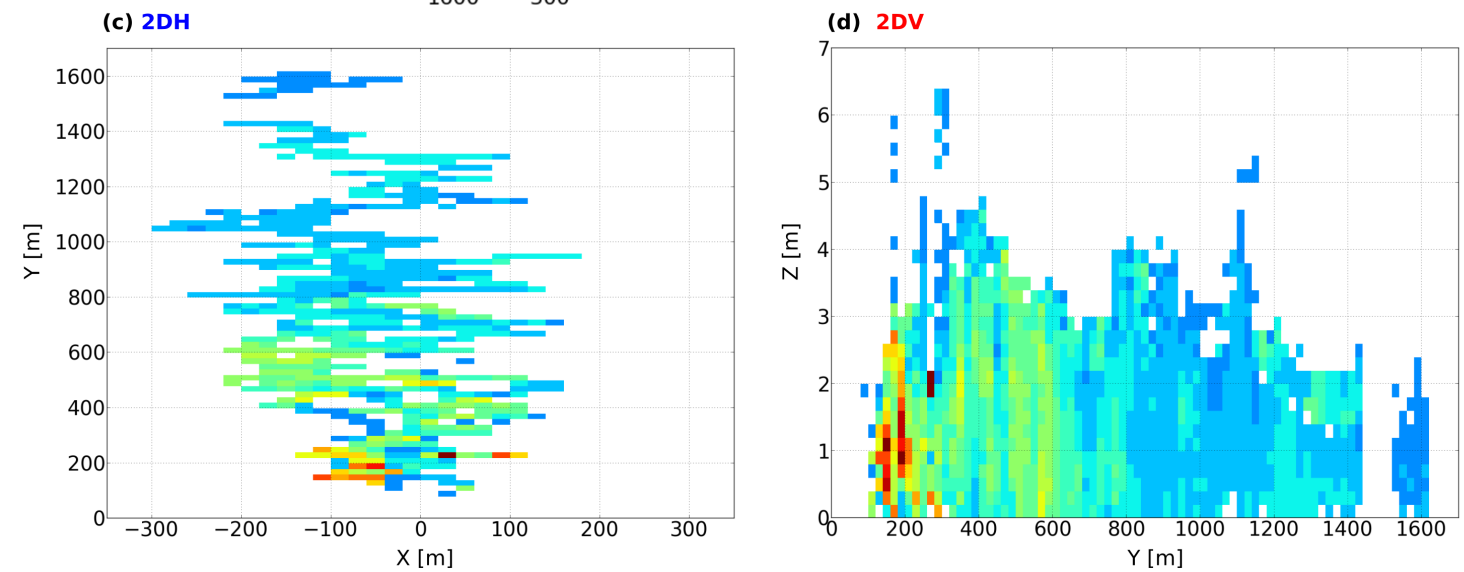

Fig. 8 OBS (Optical Backscatterance Sensor) and ADCP (Acoustic Doppler Current Profiler) data of Suspended Sediment Concentrations (SSC) obtained with the multi-sensor probe in the trawl wake. (a) 3D vision of the data, (b) representation of 2DH and 2DV averaging, and associated graphs in (c) and (d) respectively.

Horizontal and vertical averaged sections of the plume are illustrated on Fig. 8c and Fig. 8d, respectively. For those pictures, small-scale variability has been filtered by averaging $S S C$ values over $20 \mathrm{~m}$ long (in the $\mathrm{Y}$ or $\mathrm{X}$ directions) and $0.2 \mathrm{~m}$ high (in the $\mathrm{Z}$ direction) "cells". The horizontal section of the plume (Fig. 8c) is vertically averaged from 0 to $7 \mathrm{~m}$ above bottom, and only SSC values above the ambient turbidity are represented (i.e. $>5 \mathrm{mg} .1^{-1}$ ). The vertical section of the plume (Fig. 8d) represents transversal means (i.e. perpendicularly to the trawl progress axis) of SSC values behind the trawl.

In the longitudinal vertical plane, highest $S S C$ values occur between 100 and $200 \mathrm{~m}$ behind the trawl, locally reaching $200 \mathrm{mg} \cdot \mathrm{l}^{-1}$ near the seabed. Between 300 and $800 \mathrm{~m}$ behind the trawl doors, SSC values range from 30 to $80 \mathrm{mg} . \mathrm{l}^{-1}$ with an apparent vertical diffusion followed by a settling stage, while vertical gradients are low. Beyond 800 meters behind the trawl, turbidity becomes significantly lower with values around $15 \mathrm{mg} . \mathrm{l}^{-1}$ (Fig. 8d). The results obtained on the vertically averaged horizontal section are quite similar (Fig. 8c). According to Fig. 8, the plume thickness (bound by the 5 mg. $1^{-1} S S C$ contour) is between 3 and $4 \mathrm{~m}$ and reaches its maximum about $300 \mathrm{~m}$ behind the trawl. The plume length is typically $1.5 \mathrm{~km}$, while its width is in the order of $200 \mathrm{~m}$ on each side of the central axis. Moreover, the plume generation zone seems to be located near the door positions and not behind the clump (red pixels on Fig. 8c). 


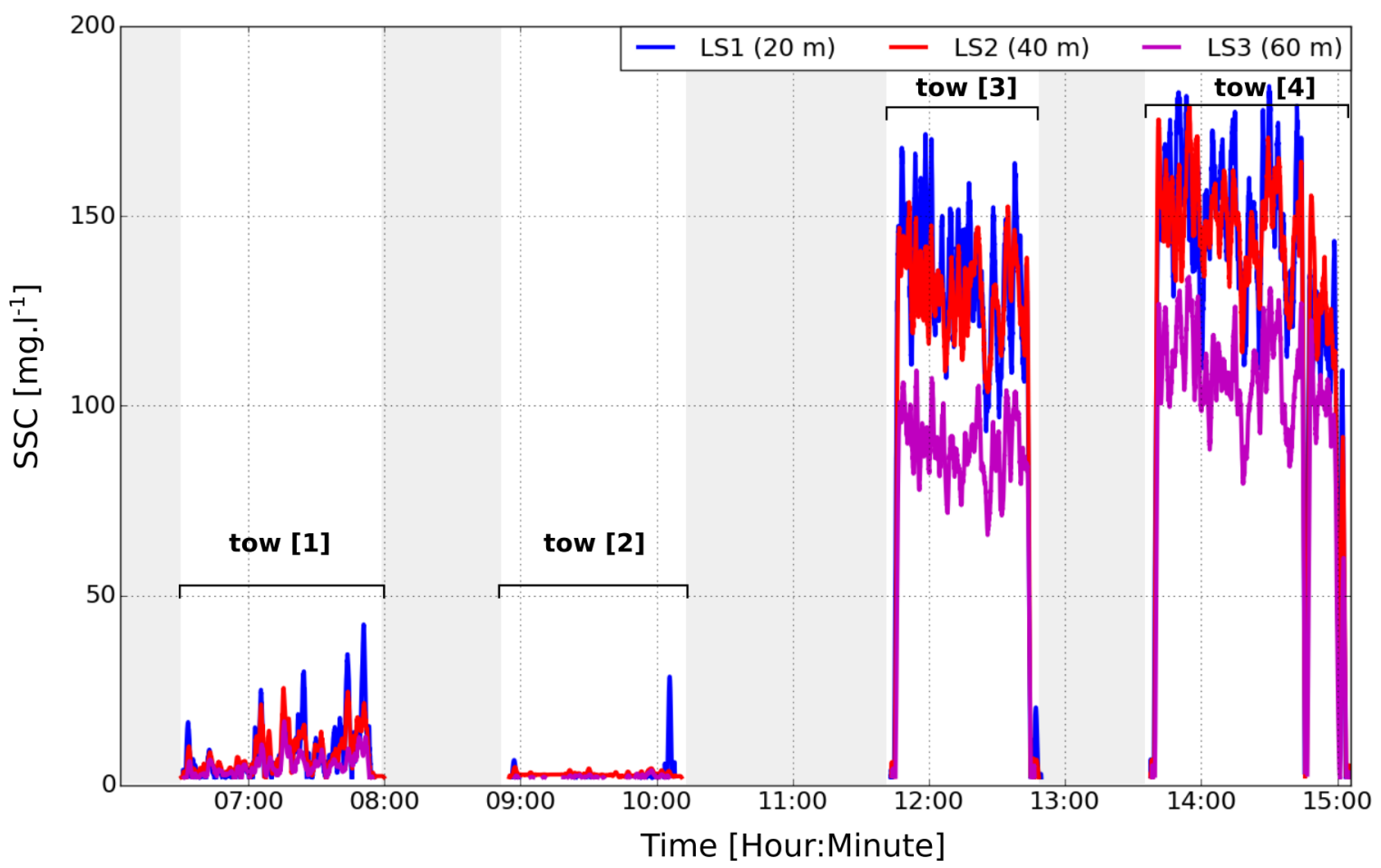

Fig. 9 Continuous SSC measurements made on zone A with the instrumented line fixed to the trawl, either behind the door (tows 3 and 4) or behind the clump (tows 1 and 2) in the configuration with classical doors.

Fig. 9 shows the data recorded by the sensors clamped to the line directly fixed to the trawl. The figure shows four trawling tows under the classical configuration, each of them lasting about one hour. During the first two tows of trawling (i.e. [1] and [2] on Fig. 9), the line was fixed to the clump (LP2). In that case, turbidity does not exceed $50 \mathrm{mg} . \mathrm{l}^{-1}$ with values around $15 \mathrm{mg} \cdot \mathrm{l}^{-1}$ at all depths: differences between the turbidity signals recorded by each sensor are low in spite of peaks detected for the one closer to the generation source (LS1). These results contrast with the situation behind the door (i.e. tows [3] and [4] on Fig. 9), where SSC values exceed $100 \mathrm{mg} . \mathrm{l}^{-1}$ most of the time and locally reach $180 \mathrm{mg} \cdot \mathrm{l}^{-1}$. Turbidity differences between sensors along the line are greater and steadier, with differences between LS1 and LS3 of about $60 \mathrm{mg} \cdot \mathrm{l}^{-1}$. LS2 turbidity levels are of the same order of magnitude as LS1 levels, but as expected, the turbidity then decreases along the line as the distances behind the trawl and above the seabed increase.

Results obtained in zone B (not illustrated here) exhibit similar SSC patterns and the same order of magnitude as in zone A.

\subsubsection{Behind the "alternative" configuration of trawl, zone A}

The number of measurement profiles is approximately the same as in the other configuration with 10 profiles of a few minutes.

Contrary to precedent results, SSC values obtained with the multi-sensor probe behind the "alternative" configuration (i.e. with "jumper" doors) range from 1 to $6 \mathrm{mg} . \mathrm{l}^{-1}$ and do not exceed the background turbidity level most of the time (then they are not illustrated here). Moreover, SSC values along the line fixed to the Jumper door (Fig. 10b) are lower (around $20 \mathrm{mg}^{-\mathrm{l}^{-1}}$ ) than behind a classical door (Fig. 10a). Few SSC peaks are punctually detected but never exceed $110 \mathrm{mg} . \mathrm{l}^{-1}$ and correspond to times when the Jumper door hits the seabed. The turbidity signal recorded behind Jumper doors is perfectly correlated with the altimetry data of the line sensors: the turbidity increases as the door moves closer to the seabed and vice versa. These results are consistent with the absence of turbidity measured by the different instruments placed on the multi-sensor probe, and prove the ability of the new gear to strongly reduce the seabed resuspension. 
(a) Behind a classical door

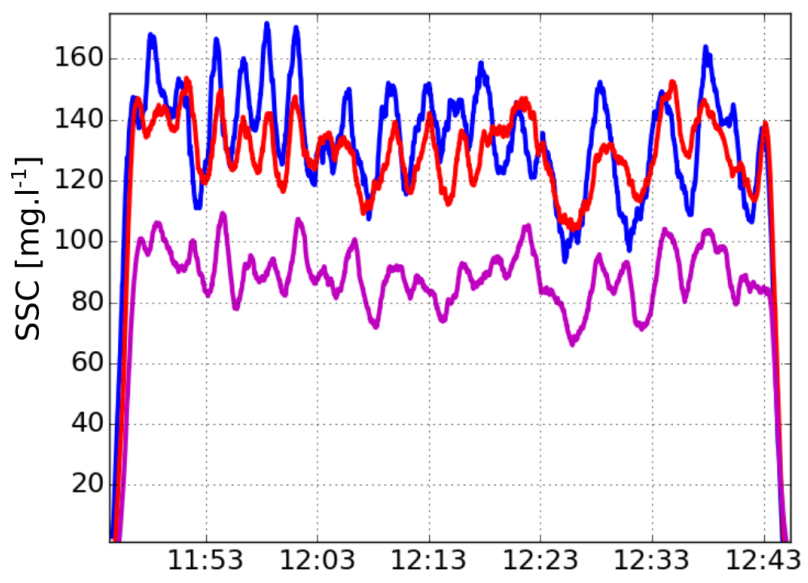

(b) Behind a jumper door

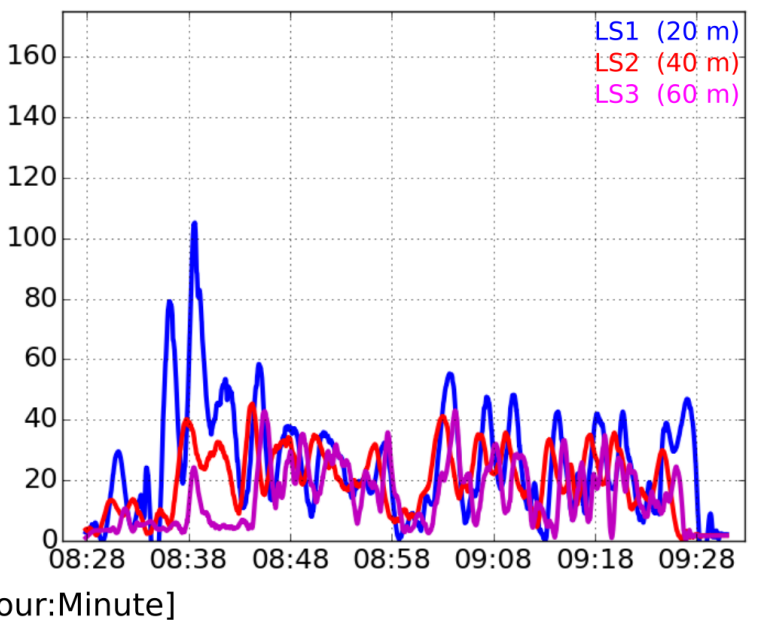

Fig. 10 Continuous $S S C$ measurements made on zone A with the instrumented line fixed (a) behind a classical door (Thyboron), and (b) behind a "Jumper" door.

\subsection{Evaluation of sediment reworking by video observations}

\subsubsection{Video acquisitions}

Following the approach described by O'Neill et al. (2009), a video sledge equipped with two cameras and three lasers was deployed to evaluate the trawling-induced disturbances on the seabed micro topography, particularly to assess the characteristics of the tracks left by the different constituents of the trawl. The experimental protocol consisted in towing the sledge $\left(0.5 \mathrm{~m} . \mathrm{s}^{-1}\right)$ across the trawl tracks generated the day before, during the experiment dedicated to plume observations.

The disturbances height is deduced from the distortion of the print left on the floor by an inclined laser beam in the field of the camera [a laser stripe (Laser 1 on Fig. 11). The laser beam is projected on the seabed with an angle of $42.8^{\circ}$ in the field of a GoPro Hero 2 camera (Camera 1 on Fig. 11), 1280×960 pixels, 48 frames per second] looking downward perpendicularly to the seabed. This print constitutes an illuminated stripe on all consecutive pictures, which is distorted by the seabed topography: holes lift the laser stripe position in the picture, whereas bumps lower it. To interpret this laser distortion in terms of elevation changes (penetration depth), a calibration of the picture is required. The transfer function is dependent on the inclination of the laser beam and the location of any picture pixels in the actual horizontal field of the camera on the seabed. The latter is deduced from a calibration procedure in the laboratory, following Darboux and Huang (2003) and O'Neill et al. (2009). The methodology has been validated by placing different shapes of known dimensions in the laser stripe plane. The resulting accuracy is close to $1 \mathrm{~mm}$. 
(a)

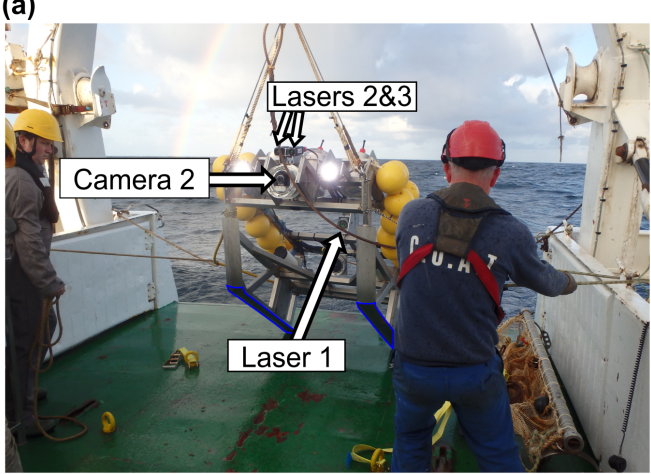

(b)

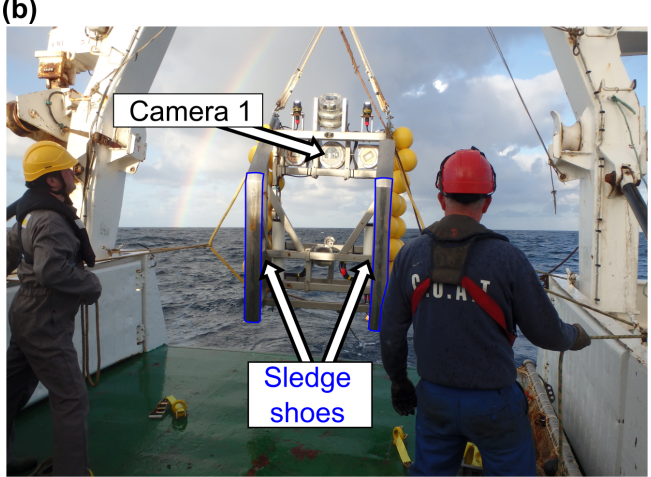

(c)

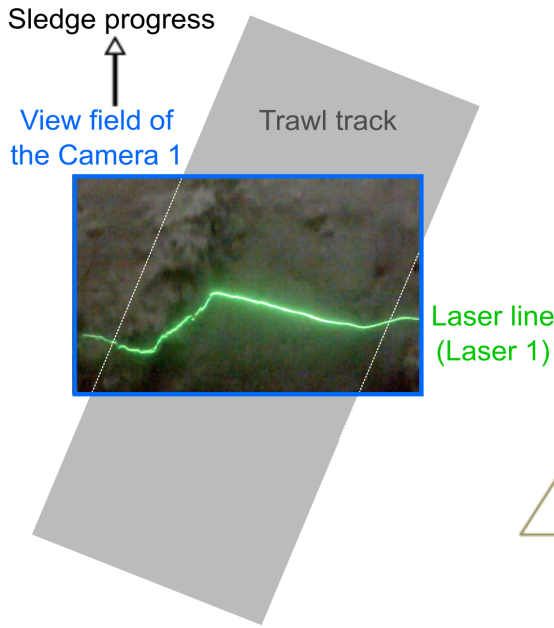

(d)

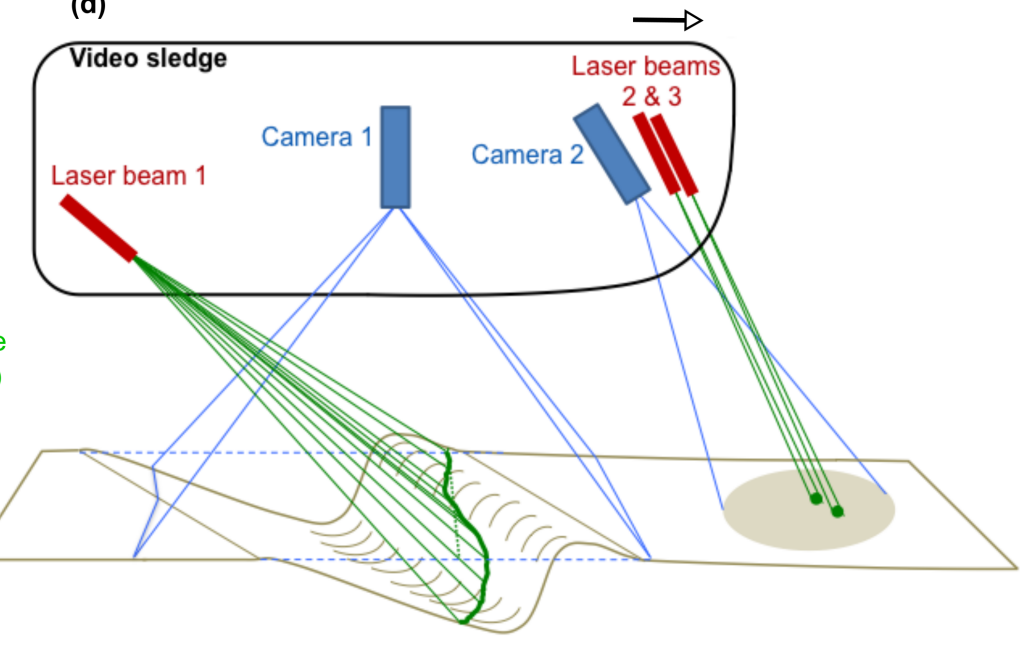

Fig. 11 Video acquisitions with a benthic video sledge during sea trials so as to quantify the trawling-induced micro-topography disturbances. The sledge as well as the different lasers and cameras are illustrated on (a) and (b). An example of the laser stripe 1 projected on the view field of the camera 1 and distorted by a trawl track is presented on (c). A global schematic view of the device is illustrated on (d).

Swell action or seabed natural topography (which may modify the penetration depth and hence increase the magnitude of microtopographic gradients) can generate changes in the sledge inclination. The relative seabed elevation, which has been calibrated in the laboratory assuming a bed parallel to the sledge, has to be corrected to account for this kind of additional inclination. This can be achieved by illuminating two spots with two additional laser beams (Lasers 2 and 3 on Fig. 11) in the field of a second camera (Panasonic camera 2 on Fig. 11), in front of the sledge. A linear relationship between the inclination angle and the distance between the two laser dots was derived and permitted to include this angular correction in the computation of the seabed elevation (Draye et al. 2015).

\subsubsection{Evaluation of an experimental erosion rate induced by bottom trawling}

Based on the exploitation of the video sequences, several tracks have been reconstituted and characterised by a mean vertical section. Results highlight $4-5 \mathrm{~cm}$ deep and $20 \mathrm{~cm}$ wide asymmetric tracks that can be directly related to the door action on the seabed. Results are synthetized on Fig. 12 with the representation of 4 typical track sections in zones A and B. In the literature, groundropes are generally mentioned as the second most impacting constituent. In our case, groundropes do not leave significant tracks and seem to only flatten the seabed: video observations reveal wide smoothed areas with an apparent decrease in burrow density, which may be due to this flattening action. 


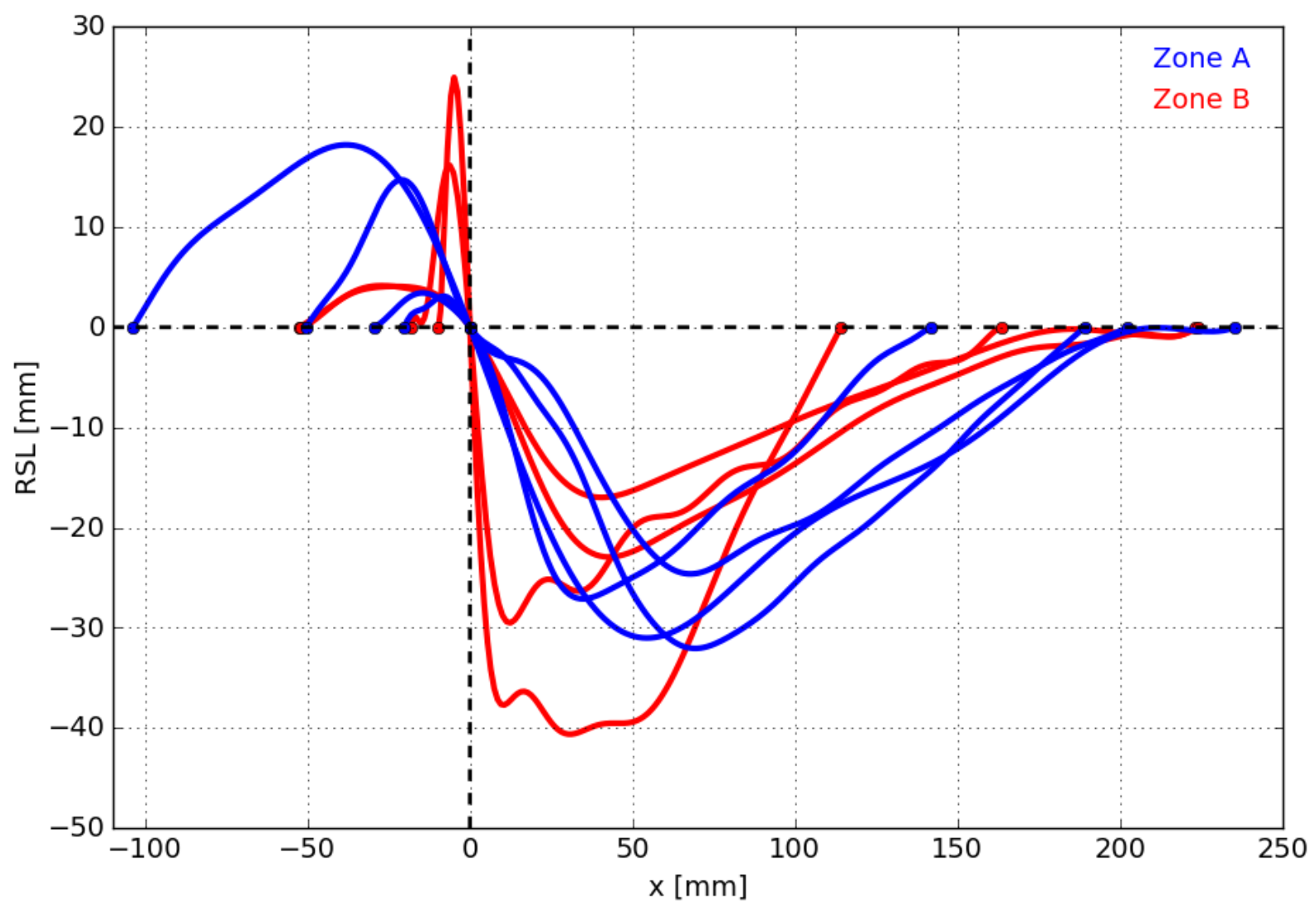

Fig. 12 Door track profiles obtained thanks to video sledge images analyses. Results are presented in terms of Relative Seabed Level $(R S L)$ along the print of the laser beam, the reference level corresponding to a horizontal vision field of the camera $(x)$. Dark blue curves are linked to the results acquired on zone A and red curves to the ones obtained on zone B.

Since the doors are the most impacting elements of the gear, the topography changes due to their penetration are assumed to represent most of the sediment displacement due to trawling. An experimental erosion rate induced by bottom trawling has therefore been computed from the vertical profiles of the Relative Seabed Level (RSL) obtained across the door tracks (the $x$ dimension in following computations). The integration of the seabed elevation regarding a reference level has permitted to deduce the surface linked to resuspended sediments. The reference level, specific to each video image, corresponds to the mean level of the undisturbed seabed on both sides of the track. Combined with other parameters such as bottom sediment concentration, track geometry, and scraped surfaces, an erosion rate is finally deduced.

As visualised on Fig. 12, the impacted seabed can be split into an accumulation part and a scour part which can be integrated along the $x$ axis. Their difference represents the cross-area of the resuspended sediment, and can be computed as the integral of RSL along the track profile ( $>0$ when accumulation, $<0$ when scour):

$S_{R E S}=\int_{x_{\text {track }}} R S L(x) d x$

This computation does not account for the deposition of particles from the plume: it is assumed that these deposits are spread over a width in the range of the plume width (typically 200 m, Figs. 5 and 8), much larger than the track width so that the reference level determination implicitly accounts for the plume deposition.

Considering that the two doors are the only significant sources of resuspension, the eroded mass per unit trawling track $\left(\mathrm{kg} . \mathrm{m}^{-1}\right)$ is $2 . C_{\text {sed }} S_{R E S}$, where the total bottom sediment concentration $C_{\text {sed }}$ is 
assumed to be uniform in each zone, and is deduced from averaging water content analyses made on seabed samples (Section 2.2), that is $1540 \mathrm{~kg} \cdot \mathrm{m}^{-3}$ in zone A and $1380 \mathrm{~kg} \cdot \mathrm{m}^{-3}$ in zone B.

The fishing effort is often expressed as a bed surface impacted by trawling during a given period of time within a given area. In order to express the fishing effort in terms of suspended sediment mass, we define an erosion rate, in $\mathrm{kg} \cdot \mathrm{m}^{-2}$, representing the resuspended mass per unit area, which can be expressed as

$$
E=2 . C_{s e d} \cdot S_{R E S} / L_{r e f}
$$

where $L_{r e f}$ represents the width along which erosion occurs behind the trawl. According to the literature, this width may differ: either it represents the total width $L_{\text {total }}$ of a trawling trace, i.e. including the distance between doors $D$ and the door tracks widths $L$, or the width $L_{s d g}$ of sediment actually impacted by the trawling gears (for instance the doors and groundropes, whose respective widths on the track are $L$ and the wing aperture $W A$ ). In our twin trawl configuration, $L=0.20 \mathrm{~m}, D=$ $50 \mathrm{~m}$ and $W A=7 \mathrm{~m}$, leading to $L_{\text {total }}=50.4 \mathrm{~m}$ and $L_{\text {sdg }}=14.4 \mathrm{~m}$.

In this general formulation, we consider the eroded sediment as a sand mud mixture. Among the different types of particles injected in the water column, the coarser ones are assumed to settle rapidly while only fine particles are assumed to contribute to the turbid plume dynamics.

This quantity of resuspended fine particles $\left(E_{m u d}\right)$ can be computed as:

$E_{\text {mud }}=M C \cdot E$

where $M C$ refers to the mud content $(<63 \mu \mathrm{m})$ in the surficial sediment. The results obtained on the two zones are summarised in Table 2 . The erosion rates (including all particle classes) obtained from Eq. (3) range between $0.12 \mathrm{~kg} \cdot \mathrm{m}^{-2}$ on zone B and $0.14 \mathrm{~kg} \cdot \mathrm{m}^{-2}$ on zone A when considering the whole distance between doors $L_{\text {total }}$ (hereinafter called $E_{\text {trawl }}$ ), and between $0.42 \mathrm{~kg} . \mathrm{m}^{-2}$ on zone B and 0.50 $\mathrm{kg} . \mathrm{m}^{-2}$ on zone A using the width of sediment swept by doors and groundropes $L_{\text {sdg }}$ (hereinafter called $\left.E_{s d g}\right)$. The fine particles erosion rates are proportional to the overall erosion rates, according to the seabed mud content (15\% and $25 \%$ for zones A and B respectively). $E_{\text {trawl mud }}$ and $E_{\text {sdg mud }}$ are thus obtained while considering $E=E_{\text {trawl }}$ and $E=E_{\text {sdg }}$ in Eq. (4) respectively (see Table 2).

Table 2 Erosion rates estimates in $\mathrm{kg} \cdot \mathrm{m}^{-2}$ on the two zones (A and B)

\begin{tabular}{ccccc}
\hline & $E_{\text {trawl }}$ & $E_{\text {trawl mud }}$ & $E_{\text {sdg }}$ & $E_{\text {sdg mud }}$ \\
\hline Zone A & $0.14 \pm 0.028$ & $0.02 \pm 0.004$ & $0.50 \pm 0.099$ & $0.08 \pm 0.015$ \\
Zone B & $0.12 \pm 0.030$ & $0.03 \pm 0.007$ & $0.42 \pm 0.108$ & $0.10 \pm 0.027$ \\
\hline
\end{tabular}

\section{Comparisons between natural- and trawling-induced erosion fluxes}

The relative contributions of the trawling-induced and natural erosion dynamics are discussed over the GV area. After a brief description of the natural- and trawling-induced erosion flux computations, results linked to comparisons are presented at different spatio-temporal scales.

\section{$\underline{4.1 \text { A simple model for wave and current resuspension }}$}

The natural erosion flux computation requires the quantification of bottom shear stresses induced by waves and currents $(\tau)$ and the choice of an erosion law. The shear stress is provided by a 3D flow model and a phase-averaged wave model, and its detailed computation is given in Appendix 2. 
In order to fit the spatial and temporal resolution of fishing effort data, hourly values of total bottom shear stress computed on a $2.5 \mathrm{~km}$ resolution grid were used to estimate natural erosion fluxes according to Eq. (5), which were then averaged from month to month along two years (2008 and 2009). These natural erosion fluxes have been computed using the "Partheniades form" of the erosion law of the muddy sand bed.

$E_{\text {nat }}=E_{0}\left(\frac{\tau}{\tau_{c r}}-1\right)^{n}$ if $\tau \geq \tau_{c r}$

The erodability parameter $E_{0}$ depends on the sediment properties. As mentioned in Ferré et al. (2008), values from the literature range between $10^{-5}$ and $2 \times 10^{-3} \mathrm{~kg} \cdot \mathrm{m}^{-2} \cdot \mathrm{s}^{-1}$ (Mulder and Udink 1991; Amos et al. 1992, 1997; Widdows et al. 1998). Simulating fine sediment transport along the continental shelf of the Bay of Biscay, Tessier et al. (2008a) applied the Partheniades erosion law but used an even lower erosion constant $\left(E_{0}=1.3 \times 10^{-6} \mathrm{~kg} \cdot \mathrm{m}^{-2} \cdot \mathrm{s}^{-1}\right)$. Ferré et al. (2008) used $E_{0}=10^{-5} \mathrm{~kg} \cdot \mathrm{m}^{-2} \cdot \mathrm{s}^{-1}$ to compute erosion fluxes at the overall scale of the Gulf of Lions. For an easier comparison with their results, we selected the same value: since the integrated erosion rate is proportional to this erosion constant, the sensitivity of our results to this constant will be easily assessed in the discussion. On the other hand, the evaluation of $\tau$ is dependent on the unknown roughness length. Computations have been run with a uniform value of $5 \times 10^{-4} \mathrm{~m}$. This value can represent the skin roughness of a coarse sand, or a form roughness of a fine sand. It may lead to an overestimation of the relevant bottom shear stress for fine sand resuspension. The critical bed shear stress $\tau_{c r}$ is set to $0.15 \mathrm{~N} . \mathrm{m}^{-2}$ according to the Shields diagram for $200 \mu \mathrm{m}$ fine sand. At last, the exponent $n$ is set to 1 , considering it is a common value used for mud, and many often for fine sediment (e.g. Beach and Sternberg 1988). In this computation, all particle classes are eroded simultaneously, and the erosion flux of fine particles is proportional to their content.

4.2 Methodology for assessing the spatial and temporal distribution of trawling-induced resuspension

\subsubsection{Fishing effort data}

The fishing effort estimate is based on VMS data (GPS-based Vessel Monitoring System). European fishing vessels longer than $15 \mathrm{~m}$ have been progressively equipped with VMS since 2005 (EC Council Regulation $\mathrm{N}^{\circ} 2244 / 2003$ of 12/18/2003). This regulation has been extended to vessels longer than 12 $m$ in 2012 (EC Council Regulation $N^{\circ} 1224 / 2009$ of 11/20/2009). We used authorized and anonymous VMS data as obtained from the French fisheries authorities (DPMA) and covering all recorded fishing vessels operating in the French Exclusive Economic Zone from 2005 to 2013, so as to quantify the distribution and intensity of trawling over the whole studied area. Raw VMS data provide 5 types of information: "anonymous" vessel individual code, date and hour, latitude and longitude, instantaneous speed in knots and vessel heading. The VMS dataset included additional information regarding the gear types, vessels overall length and power classes as declared in the EU logbooks and the EU Fishing fleet register (http://ec.europa.eu/fisheries/fleet/).

In order to discriminate the current type of activity for each vessel (e.g. fishing or transit), we used criteria widely and successfully applied in many previous studies (e.g. Lee et al. 2010; Gerritsen and Lordan 2010; Gerritsen et al. 2013): trawling is assumed whenever the mean speed is above 0 and under 4.5 knots and the elapsed time between two successive points is less than 6 hours. Vesselfishing tracks were reconstructed from spline curves through successive VMS positions affected to fishing operations (Hintzen et al. 2010). Different publications stressed that reconstituted vessel tracks by straight-line or spline interpolations could deviate from real tracks (e.g. Skaar et al. 2011; Lambert et al. 2012). In our case, the uncertainty due to the low frequency of VMS transmissions is reduced by a 1 hour time interval between data, shorter than the classical 2 hours periodicity, while the typical duration of a trawling operation is about 3 to 4 hours (Cornou et al. 2015). In addition, the Métiers specificities (type of bottom trawlers) and fishing grounds (relatively homogeneous strata) of our 
studied area lead to mostly rectilinear fishing tracks that should be correctly estimated from spline interpolations. Alternative source of data like AIS (Automatic Identification System) could provide a position record every $6 \mathrm{~s}$ and enable a very accurate reconstitution of vessel track (Oberle et al. $2015 a, b)$. Such high temporal resolution data could constitute a valuable improvement to fishing effort estimates but they were not available for most of our study site.

The total trawled area was estimated from VMS dataset using the method described by Eigaard et al. (2015). Only twin and single otter trawls were considered as they represent close to hundred per cent of trawling gears over the GV. The other types of gears (statics and seine gears) were considered as having negligible impacts on the seafloor. Thus, fishing effort has been computed taking into account typical trawled width (representative of the distance between doors) for each kind of fishing gear and vessels category. Multiplying that width by the reconstituted tracks length provides an estimate for the trawled surface area. A 1' resolution grid was defined in order to compute fishing effort from VMS dataset. That resolution was proven to ensure randomly distributed effort inside each cell (Rijnsdorp et al. 1998). For each cell, the total trawled surface area on the seafloor was computed as the sum of these individual trawled surfaces. Estimates from the initial fine-scale data grid have been aggregated to larger grid cells $\left(25 \mathrm{~km}^{2}\right)$ thus reducing the effects of misattribution of fishing effort into adjacent grid cells. In this study, the fishing effort forcing $(F E)$ is thus expressed in $\mathrm{km}^{2}$ swept per month and per cell of $25 \mathrm{~km}^{2}$ each, and can be transformed in fraction of trawled seabed per second. Considering available dataset and identified sources of errors (speed rules to detect fishing events, reconstruction, size of aggregation grid cells), we can reasonably consider that VMS data and utilised methods as acceptable when compared to the objectives of our study and especially the time and space scale required.
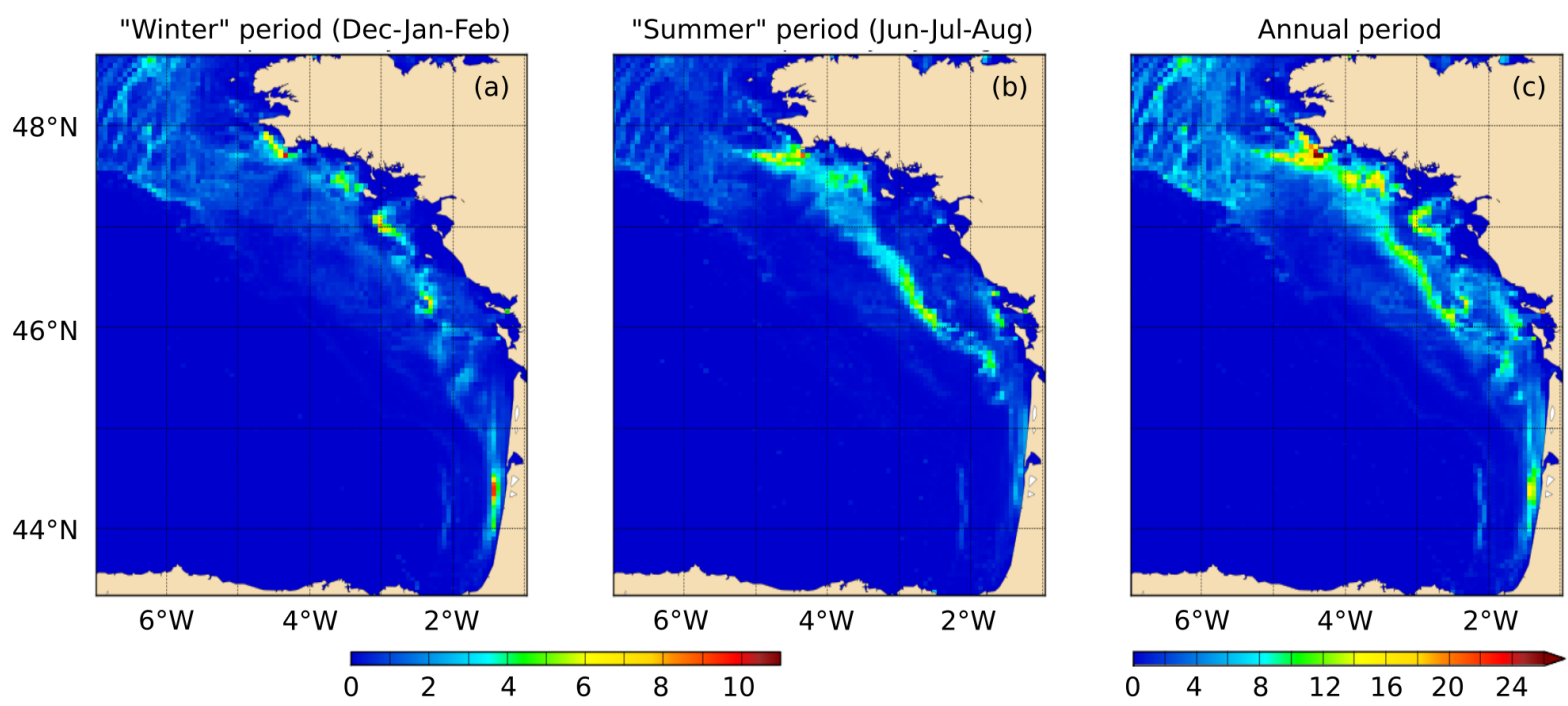

Fig. 13 Maps of fishing effort from VMS data (horizontal resolution of $5 \mathrm{~km}$ ) expressed in number of times of trawling within given periods: (a) "winter" period (from December to February), (b) "summer" period (from June to August), and (c) at the annual scale. Cumulated values were obtained from a trawling "climatology" corresponding to averages of monthly cumulated fishing effort data realised over the 2005-2013 period. For instance, a value higher than 1 means that the spot is trawled more than one time during the considered period.

Cumulated maps (Fig. 13) highlight that trawling activities are concentrated on restricted areas bordering the inner part of the GV in winter (from December to February, Fig. 13a). Nevertheless, winter-integrated fishing effort is relatively intense over these areas and some cells are swept between 4 and 8 times during that period (locally 11 times). Summer trawling activities (Fig. 13b) occur on larger and deeper areas than in winter, further offshore and centred on the internal part of the GV (i.e. until $120 \mathrm{~m}$ depth). Corresponding cells on the summer-integrated fishing effort map are trawled between 3 and 7 times (locally 9 times) between June and August. Lastly, the annually integrated fishing effort map (Fig. 13c) shows that both winter and summer preferential trawled areas remain still visible with cells mainly swept between 10 and 16 times (up to a maximum of 45 times). 


\subsubsection{Regional trawling-induced resuspension}

Considering that trawling-induced erosion rates are similar in zones A and B (respectively 0.14 and $0.12 \mathrm{~kg} \cdot \mathrm{m}^{-2}$ ), and assuming they remain representative of muddy sand facies which are dominant in the $\mathrm{GV}$, a uniform distribution of $E_{\text {trawl }}\left(=0.13 \mathrm{~kg} \cdot \mathrm{m}^{-2}\right)$ has been adopted.

The combination of this experimental erosion rate deduced from door tracks $\left(E_{\text {trawl }}\right.$, in $\left.\mathrm{kg} . \mathrm{m}^{-2}\right)$ with fishing effort data $\left(F E\right.$, in $\left.\mathrm{s}^{-1}\right)$ allows the estimation of a regional (i.e. distributed at the scale of the $\mathrm{GV}$ ) trawling-induced erosion flux $\left(E_{\text {regional trawl }}\right.$, in $\left.\mathrm{kg} \cdot \mathrm{m}^{-2} \cdot \mathrm{s}^{-1}\right)$. It is expressed as:

$E_{\text {regional trawl }}=E_{\text {trawl }} \times F E$

Indeed, both the experimental erosion rate $E_{\text {trawl }}$ (section 3.3.2) and the fishing effort $F E$ (section 4.2.1) used in Eq. (6) are related to the total trawled area (i.e. distance between doors are considered in their respective computation). For both natural and trawling-induced erosion processes, total sediment (sand and mud) is considered.

Oberle et al. (2015a) have recently proposed a general formulation of trawling-induced erosion rates (in $\mathrm{kg} . \mathrm{m}^{-2}$ ) as a function of the seabed composition (i.e. grain size-specific substrate type, average silt and clay content) from many available erosion rate estimates existing in the literature (evoked in the discussion section 5.3; i.e. Churchill 1989; Durrieu de Madron et al. 2005; Dellapenna et al. 2006; Dounas et al. 2007; O'Neill and Summerbell 2011). Such relation would be helpful to compute trawling-induced erosion rates at more extended spatial scale (e.g. the global analysis performed by Oberle et al. 2015a), while the sediment cover heterogeneity has to be taken into account. In the present case, the relative uniformity of surficial sediment in the "Grande-Vasière" area allowed the use of a specific trawling induced erosion rate calibrated on the representative trawlers of the area.

\subsection{Results: respective weights of natural and trawling induced resuspension on the whole area}

The comparison is based on erosion fluxes averaged along specific periods, months, years, or seasons (winter/summer) for the two years 2008 and 2009. Estimates are proposed over given bathymetric ranges within the GV contours. Fig. 14 illustrates maps of averaged erosion fluxes at the annual scale, and during the "winter" (from December to February) and "summer" (from June to August, i.e. high season of fishing) periods. In order to make interpretations easier, these erosion fluxes (annual and seasonal means) induced by natural and anthropogenic forcing are averaged over given bathymetric ranges (i.e. between 60-80, 80-100, 100-120, 120-140, 140-160, and 160-180 m depth; Fig. 15). Lastly, a comparison of monthly averaged erosion fluxes is presented over the most intensively trawled part of the GV area, more precisely between 90 and $120 \mathrm{~m}$ depth (Fig. 16).

At the scale of the GV, the dominance of wave forcing on the current one can be underlined, as shown by respective computations from the flow model and the wave model (not illustrated here). Natural resuspension fluxes decrease with increasing water depth, especially because of lower wave-induced bottom shear stresses. However, the resuspension decrease moving offshore varies seasonally. Winteraveraged natural erosion fluxes decrease 30 times between the $60-80 \mathrm{~m}$ bathymetric range and the $160-180 \mathrm{~m}$ one (Fig. 15). This trend is more pronounced during the summer down to the $100-120 \mathrm{~m}$ bathymetric range. Beyond $120 \mathrm{~m}$ depth, the decrease trend becomes more progressive. This strong decrease during summer (i.e. low energetic conditions) can be explained by more pronounced gradients of excess wave-induced shear stress, wave-induced shear stress being then closer to the critical stress for erosion. High values are confined on the eastern side of the GV and rapidly reduce with increasing water depth (Figs. 14, 15). More generally, winter averaged erosion fluxes are 6 to 25 times higher than summer averaged values between 60 and $100 \mathrm{~m}$ depth and they are around 100 times higher beyond $100 \mathrm{~m}$ depth. Integrated natural erosion fluxes along the whole year or during 3 months 
in winter exhibit comparable values. These observations confirm that the action of waves and currents induced by winter storms mainly controls the annual natural dynamics over the GV.
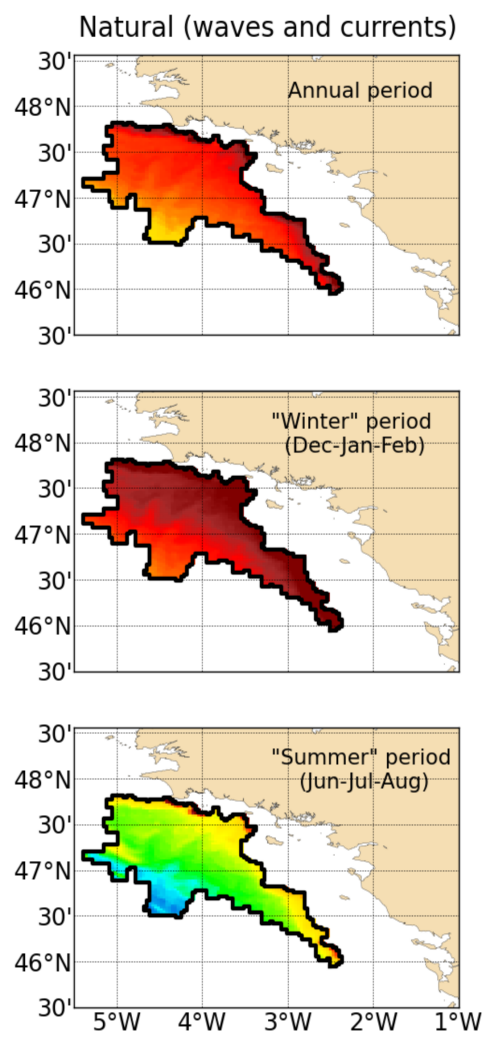
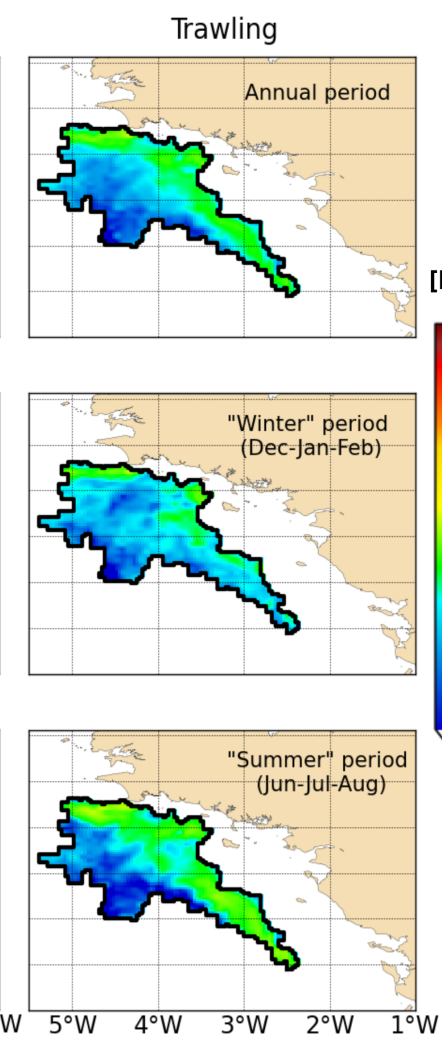

Trawling/Natural

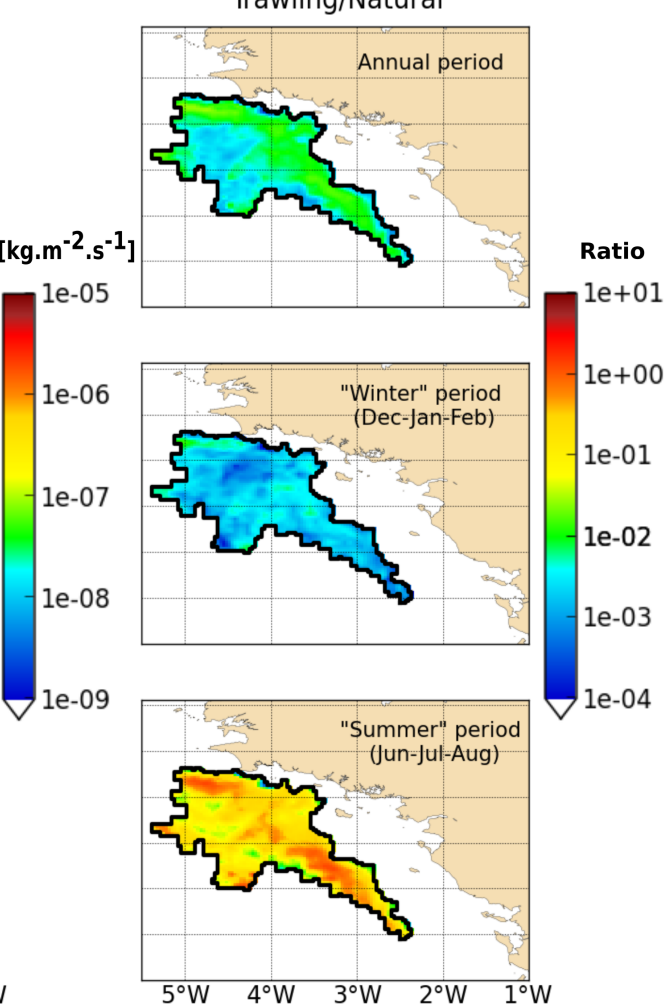

Fig. 14 Maps of temporally averaged resuspension fluxes computed for both natural and anthropogenic forcings at the scale of the GV, as well as the corresponding ratio. Fluxes are averaged at the seasonal (i.e. winter and summer) and annual scales.

Trawling-induced erosion fluxes decrease moving offshore with a trend depending on the season. In winter, they regularly decrease from $3.5 \times 10^{-8} \mathrm{~kg} \cdot \mathrm{m}^{-2} \cdot \mathrm{s}^{-1}$ between 60 and $80 \mathrm{~m}$ depth to $5 \times 10^{-9} \mathrm{~kg} \cdot \mathrm{m}^{-2} \cdot \mathrm{s}^{-1}$ on the 140-180 m bathymetric range. However, in summer, they appear relatively uniform between 60 and $120 \mathrm{~m}$ depth with values around $4 \times 10^{-8} \mathrm{~kg} \cdot \mathrm{m}^{-2} \cdot \mathrm{s}^{-1}$. They then rapidly decrease with values around $10^{-8}$ (resp. $3 \times 10^{-9}$ ) kg.m. $\mathrm{m}^{-2} \cdot \mathrm{s}^{-1}$ between 120 and $140 \mathrm{~m}$ depth (resp. 160-180 m). Thus, on the $80-120 \mathrm{~m}$ bathymetric range, summer fluxes appear 2 times higher than in winter (Fig. 15).

In winter, trawling-induced erosion fluxes are significantly lower than natural fluxes: differences range from a factor 200 between 160 and $180 \mathrm{~m}$ depth to almost three orders of magnitude in the range 60-80 m. Although seasonally-averaged trawling-induced erosion fluxes are systematically lower than natural ones, summer differences are much weaker: for instance trawling-induced erosion fluxes would be only 3 times lower than natural ones between 100 and $120 \mathrm{~m}$ depth. In addition, maps of seasonally averaged fluxes on Fig. 14 clearly highlight that trawling fluxes can appear dominant in certain regions of the GV, especially near northern and southern boundaries. 


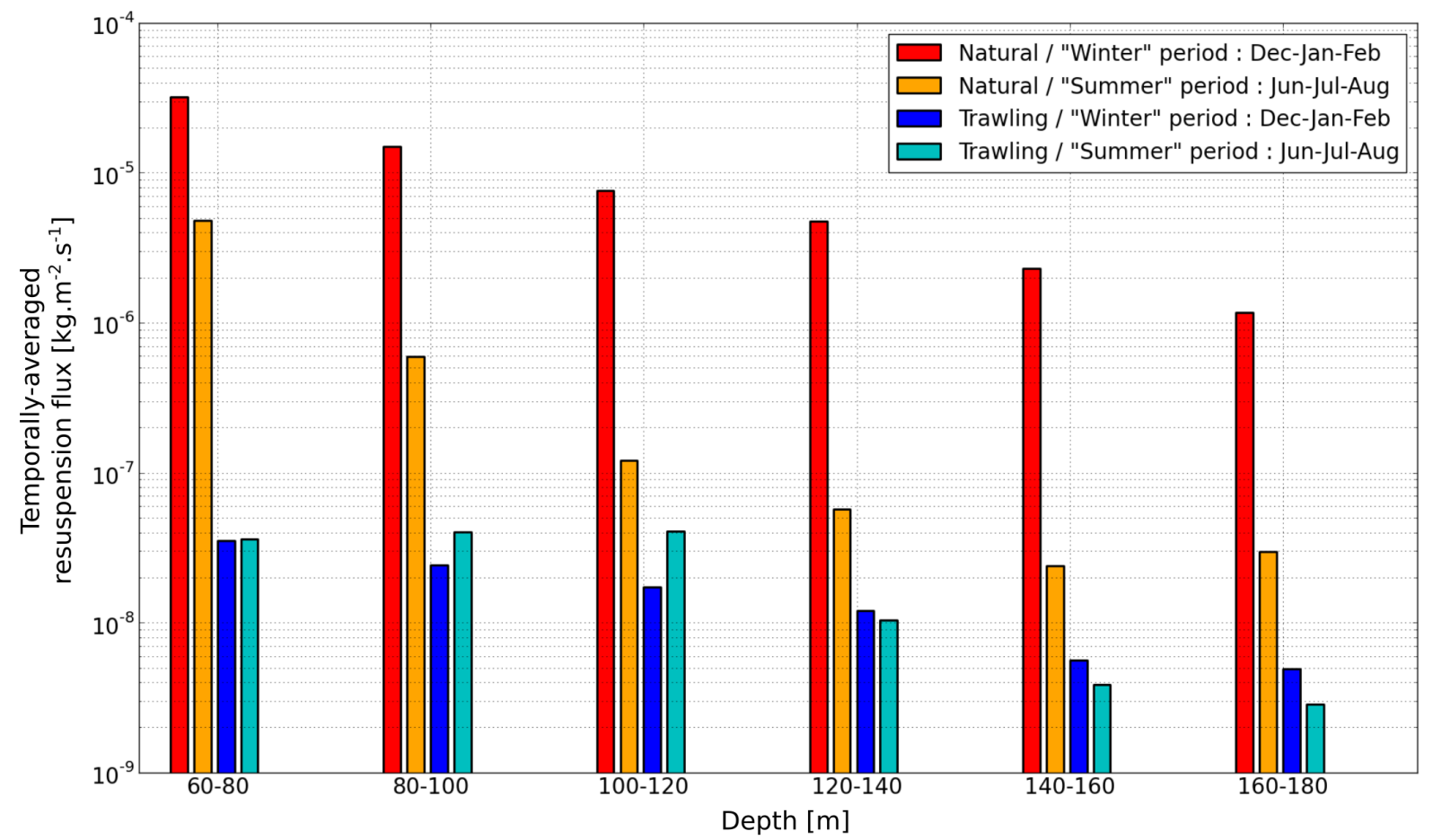

Fig. 15 Temporally averaged (over time and over bathymetric ranges) resuspension fluxes computed for both natural and anthropogenic forcings during the winter and summer seasons.

Fig. 16 provides a detailed vision (monthly averages under actual forcing) of both natural and anthropogenic erosion fluxes on the bathymetric range where the differences are the weakest, set here between 90 and $120 \mathrm{~m}$ depth. First it can be seen that variations of natural and anthropogenic erosion fluxes describe annual cycles, which are nearly in opposition of phase. The high season of fishing comes up during late spring/summer season and is characterised by the highest trawling-induced erosion fluxes with values around $5 \times 10^{-8} \mathrm{~kg} \cdot \mathrm{m}^{-2} \cdot \mathrm{s}^{-1}$ for both years (occurring in June 2008 and May 2009 respectively). On the contrary, the lowest trawling-induced erosion fluxes come up during the winter period with values of $1.2 \times 10^{-8} \mathrm{~kg} \cdot \mathrm{m}^{-2} \cdot \mathrm{s}^{-1}$ in January 2008 and $10^{-8} \mathrm{~kg} \cdot \mathrm{m}^{-2} \cdot \mathrm{s}^{-1}$ in January 2009 . In that bathymetric range, trawling-induced erosion fluxes are thus smaller during autumn and winter by a factor ranging between 2 and 5. On Fig. 16, the dotted line represents the monthly-averaged trawling-induced erosion fluxes computed with a fishing effort climatology realised over the 20052013 period. Given that corresponding estimates are similar to the ones obtained with the actual fishing effort during the 2008 and 2009 years, the latter years can be considered as representative of trawling effects, which supports the idea that the comparison is not performed during atypical years from the trawling point of view. Regarding natural dynamics, the highest values generally occur in winter. Natural erosion fluxes then exceed the trawling-induced ones by 2 to 3 orders of magnitude. On the contrary, the lowest natural fluxes come up in late spring (May 2008 or June 2009). During this period, trawling-induced erosion fluxes can exceed natural ones during one to two months. Although bottom trawling can be punctually dominant, at the summer scale (Fig. 14) its contribution represents around $30 \%$ of the natural erosion over the 90-120 m bathymetric range of the GV, with the chosen hypotheses on $z_{0}$ and $E_{0}$ (see discussion). As shown by Fig. 16, the inter-annual variability of natural erosion fluxes during spring/summer months is likely to modify the relative contribution of bottom trawling. Moreover, the annual contribution of trawling can vary locally with highest values near the northern and southern boundaries of the GV (Fig. 14).

On average, the amount of sediment resuspended by natural forcing (i.e. waves and currents) at the annual scale or during the winter season is largely dominant over the GV. Depending on the bathymetric range, averaged natural erosion fluxes exceed the trawling-induced ones by 2 to 3 orders of magnitude in winter and at the annual scale (Fig. 14). However, our results underline how trawlinginduced erosion can dominate the natural-induced one during certain months (Fig. 16) and locally during the overall high season of fishing (Fig. 14). In addition, it should be reminded that the 
resuspension induced by a door dragged on the seabed can be locally more impacting than a storm (which generally acts on more extended areas).

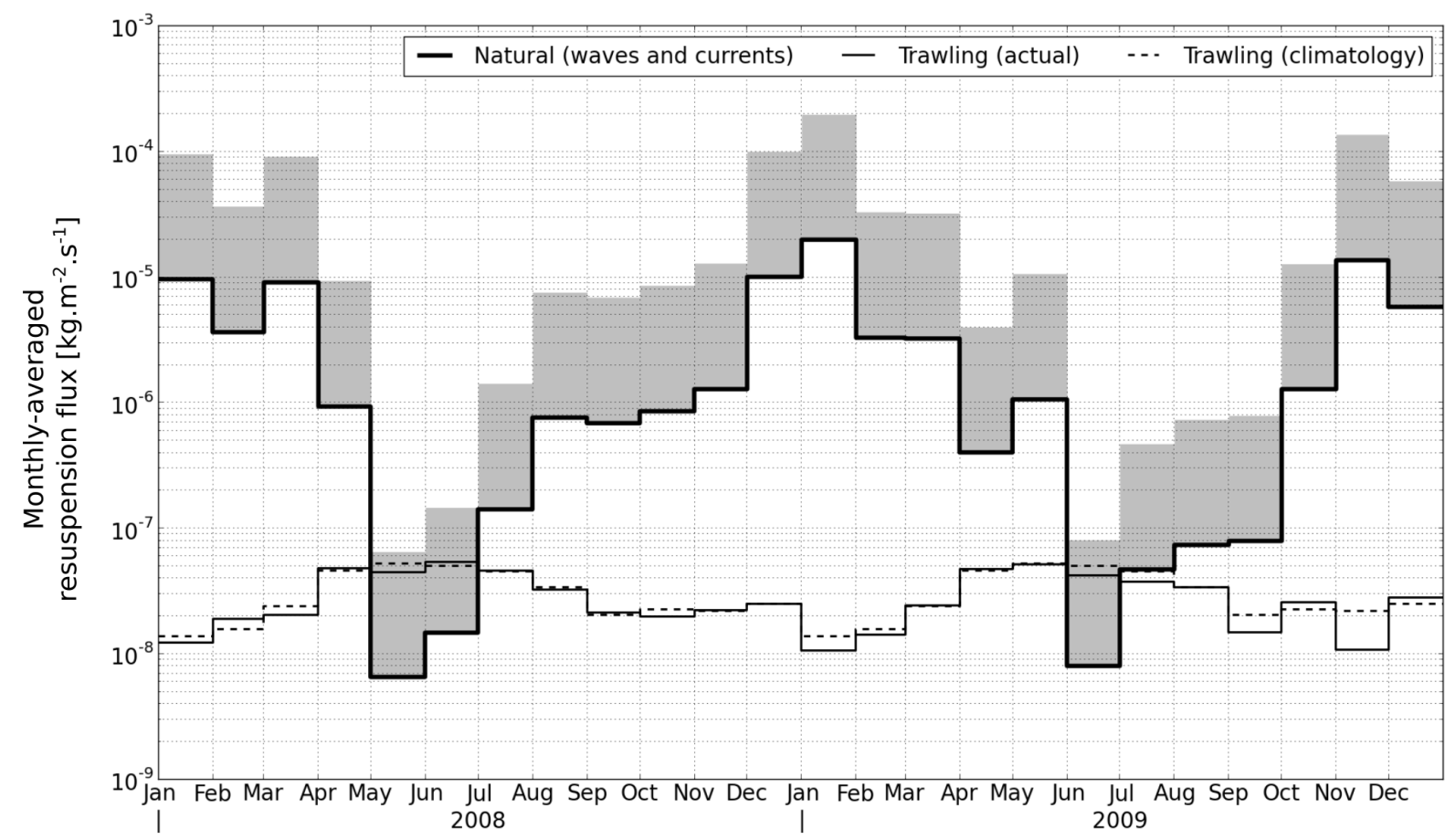

Fig. 16 Monthly averaged resuspension fluxes computed for both natural and anthropogenic forcings between 90 and $120 \mathrm{~m}$ depth (i.e. the most intensively trawled area of the GV) during two years. "Actual" trawling forcing refers to monthly cumulated fishing effort data during the two years, while the trawling "climatology" corresponds to averages of monthly cumulated fishing effort data during the 2005-2013 period. Grey bands illustrate the effect of a ten-fold increase of the erosion constant $E_{0}$ on natural erosion flux estimates.

\section{Discussion}

\subsection{Characterisation of the trawling-induced resuspension plume}

Turbidity measurements with sensors originally set up in the trawl wake permitted to identify trawl doors as the main sources of resuspension by trawling gears. This conclusion is consistent with previous observations from other study sites such as O'Neill and Summerbell (2011) who showed that trawl doors generate 60 to $70 \%$ of the total resuspension in the case of a muddy sand seabed. It confirms underwater observations from Main and Sangster (1981) as well as sonar images from Dellapenna et al. (2006) who highlighted that doors mainly initiate the resuspension in the trawl wake. Associated suspended sediment concentrations reach $200 \mathrm{mg} \cdot \mathrm{l}^{-1}$ just behind the trawl, which fits within the range of a few hundreds of $\mathrm{mg} . \mathrm{l}^{-1}$ mentioned in the literature (e.g. Schubel et al. 1979; Schoellhamer 1996; Durrieu de Madron et al. 2005; Dellapenna et al. 2006).

By using a new coordinate system aligned with the trawl and following it, a steady state representation of the plume in the trawl wake could be reconstituted. A 3-4 m high and 300-400 m wide turbid plume was observed. The plume vertical extension is in agreement with Main and Sangster (1981) conclusions who suggested that the plume height generally equals 3 times the vertical opening of the net, which is around one meter in our experiment. The plume lateral extension is of the same order of magnitude as shown in previous works (e.g. Durrieu de Madron et al. (2005) in the Gulf of Lions). In the trawl wake, vertical diffusion is responsible for the plume growth until particles settling processes dominate ( $800 \mathrm{~m}$ behind the trawl) and the plume height decreases. The length of the plume tail (behind the position of plume maximum height) $L_{\text {plume tail }}$ can be related to the time required for particles initially located at $h=3 \mathrm{~m}$ above bottom to settle at a rate $W_{s}$, through the towing speed $U_{\text {tow }}$ 
of the trawl: $L_{\text {plume tail }} / U_{\text {tow }}=h / W_{s}$. With $U_{\text {tow }}=1.6 \mathrm{~m} . \mathrm{s}^{-1}$ and $L_{\text {plume tail }} \approx 1600 \mathrm{~m}$, the settling velocity can be estimated to $3 \mathrm{~mm} \cdot \mathrm{s}^{-1}$. Since suspended sediment concentration does not exceed the ambient value beyond the considered plume length, and because some trawling-induced turbulence may remain in the trawl wake, this estimation can be considered as a minimum estimation for the settling velocity. This value is rather high for the muddy individual particles included in the plume, and too low for fine sand particles (a $200 \mu \mathrm{m}$ sand settles at $2.5 \mathrm{~cm} . \mathrm{s}^{-1}$ ), which suggests that flocculation processes do occur within the plume. However, this estimation has to be taken with caution: advection by the ambient current is likely to deviate the plume from its theoretical trajectory, so that the turbidity decrease can result from such a deviation of the plume in addition to particle settling.

"Jumper" doors are characterised by an intermittent contact with the seabed and were designed to limit resuspension without limiting fishing efficiency. SSC measured just behind these doors is about 10 times lower than behind a classical door. Consistently, nearly no excess turbidity is detected in the trawl wake. These results demonstrate that the use of alternative doors on common fishing gears significantly reduces the resuspension process. As the fishing efficiency (out of the topic of this paper) seemed to be the same as before (L. Tréguier, Pers. Comm.), it appears that the designed new door satisfies the requirement.

\subsection{Impacts on the GV seabed}

Grain size analyses carried out on sediment cores provided mean spectra and vertical profiles of mud and clay contents, $d_{10}$, and $d_{50}$ in the upper $25 \mathrm{~cm}$ for both investigated zones. The vertical profiles of grain size related parameters exhibit a relative homogeneity, especially in zone A. However, the first 3-4 cm of the surficial sediment exhibit more or less acute trends. The most intensively trawled zone (B) exhibits upward coarsening whereas the moderately trawled zone (A) only shows a higher standard deviation of grain size related parameters. These results suggest that the combined action of natural (i.e. wave, current, and bioturbation) and anthropogenic (i.e. bottom trawling) processes remodels the upper few centimetres of the sedimentary column in both zones, but induces more pronounced trends in the intensively trawled zone (B): the more intense fishing effort over this area is responsible for more significant resuspension and induces a fine fraction loss in the seabed.

Regarding the upward-coarsening trend, our results qualitatively agree with previous findings. Our observations are consistent with those of Palanques et al. (2014) who observed a $d_{50}$ upward increase in surficial sediment induced by bottom trawling. This upward-coarsening trend was observed by Oberle et al. (2015b) on the NW Iberian shelf, who assessed the lithological and structural changes induced by bottom trawling by comparing sediment core data from trawled and untrawled sites (until $50 \mathrm{~cm}$ depth). They showed lower and more variable values of clay content in sediment cores sampled on trawled sites, as well as homogeneous porosity values over sediment core depth (while pronounced gradients were found on untrawled sites). In the Southern Bering Sea (Bay of Bristol), Brown et al. (2005) showed that within fished areas, surficial sediments (down to $3 \mathrm{~cm}$ ) contained fewer fine grains and were better sorted than sediments located deeper, or located in untrawled sites.

Regarding the relative grain size vertical homogeneity observed in our sediment cores, many studies highlighted upper mixed layers of 5-10 cm thick induced by bioturbation (e.g. Wheatcroft and Drake 2003; Brown et al. 2005; Simpson and Watling 2006; Oberle et al. 2015b). In addition, some of them showed a "trawling affected layer" beyond 5-10 cm depth in sediment [e.g. down to 25-30 cm depth in Oberle et al. (2015b) in the NW Iberian shelf; between 10 and $17 \mathrm{~cm}$ depth in Simpson and Watling (2006) in the Gulf of Maine], interpreted as the effect of bottom trawling on sediment mixing and overturning. Such interpretations agree with the one of Dubrulle et al. (2007) for the GV site, who interpreted homogeneous vertical profiles of ${ }^{210} \mathrm{~Pb}$ in the upper $7-20 \mathrm{~cm}$ of sediment cores by a sediment mixing induced by the combined action of bioturbation, long-term bottom trawling effects, as well as a regular fine sediment supply (Jouanneau et al. 1999).

Time evolutions in the seabed composition were highlighted. The mud content in the intensively trawled zone (zone B) was found to have decreased by 30\% between 1967 and 2014, whereas no tendency was observed in the moderately trawled one (zone A). These conclusions agree with Bourillet et al. (2006) who mention a 4 to 6 fold increase in sand/mud ratio (i.e. a fine particle loss) 
between 1969 and 2002 in the GV. Owing to the proximity and comparable water depths of zones A and $\mathrm{B}$, spatial differences in wave regime or sediment supply between them cannot explain those differences in mud content evolution. The more intense fishing effort over zone B remains a likely explanation for this change in surficial sediment composition, in agreement with the surficial sediment coarsening induced by trawling.

\subsection{Trawl bottom tracks and determination of a trawling-induced erosion rate}

Trawl marks, especially those linked to doors, were clearly observed on side scan sonar images in both zones. They are more numerous in zone B which is coherent with the more intense fishing effort over this area. Video processing techniques were used to reconstitute the tracks vertical sections. Asymmetric door tracks of about $4-5 \mathrm{~cm}$ deep and $20 \mathrm{~cm}$ wide were clearly identified, which is consistent with results from similar investigations in mainly muddy sand beds (Linnane et al. 2000). Unlike O'Neill and Summerbell (2011) who found that groundropes contributed to up to $20-30 \%$ of the local trawling-induced resuspension, we observed that groundropes mostly flatten the seabed and their influence on resuspension could be neglected given the absence of visible tracks. Dounas et al. (2007) reported completely flattened and scraped surfaces linked to the impacts of groundropes and nets in a $100 \mathrm{~m}$ depth muddy environment in the Heraklion Bay (Cretan Sea).

The tracks cross-sections were considered to provide a proxy for the amount of resuspended sediments; they were therefore used to compute an experimental erosion rate induced by the doors scraping the seabed. The rates obtained with this method are similar in the two zones with a mean value of about $0.13 \pm 0.03 \mathrm{~kg} \cdot \mathrm{m}^{-2}$ with a mud content ranging from 15 to $25 \%$. The standard deviation linked to the erosion rate estimate is comparable to the potential resuspension induced by the other trawl parts, especially groundropes (O'Neill and Summerbell, 2011). Given that track observations were realised the day following their generation, a certain amount of sediment resuspended by the trawl has been potentially deposited in the tracks, especially sand that settles rapidly. As a consequence, our erosion rate estimation could be under-estimated. Durrieu de Madron et al. (2005) performed trawling experiments in the Gulf of Lions in $90 \mathrm{~m}$ water depth. They computed an erosion rate as the ratio between the sediment suspended mass in the plume over a given length and the area scraped by the trawl over this same length. They found resuspension rates ranging from $0.19 \mathrm{~kg} \cdot \mathrm{m}^{-2}$ for a clayey silt seabed to $0.8 \mathrm{~kg} \cdot \mathrm{m}^{-2}$ in the case of silty clay (whose mud content exceeds $80 \%$, while it was around $20 \%$ in our area). Their computation considers the surface scraped by the doors and groundropes (i.e. $L_{s d g}$ in Section 3.3.2). Then, it is more appropriate to compare these values to our $E_{s d g}$ mud parameter. In our study case, the mean $E_{s d g}$ mud value is around $0.09 \mathrm{~kg} . \mathrm{m}^{-2}$. Although in the same order of magnitude, our estimation is lower, which may be due to a lower mud content, and consequently a higher resistance to penetration. More recently, O'Neill and Summerbell (2011) estimated the mass of sediment remobilised per unit swept area behind different trawl constituents (i.e. several types of groundropes, doors) from video observations (plume dimensions) and suspended sediment concentration measurements provided by a fully-equipped experimental benthic sledge placed in the wake. They computed the hydrodynamic drag linked to each constituent. They fitted linear correlations between the hydrodynamic drag and the resuspended mass, depending on the seabed composition (sand/mud fractions). They finally proposed an estimation of the amount of resuspended sediment behind a trawl representative of the Scottish demersal whitefish fleet. When averaged over the total width between doors, resuspension rates ranged between 0.5 (sandy bottom) and 3 (sandy mud) kg.m ${ }^{-2}$. These values can be compared to our parameter $E_{\text {trawl }}$ of $0.13 \mathrm{~kg} . \mathrm{m}^{-2}$. Our estimation is thus much lower, at least by a factor 4 . In the case of sandy muds, a similar disagreement could be noticed between O'Neill and Summerbell (2011) and Durrieu de Madron et al. (2005) estimates, with respective erosion rates of 3 and $0.8 \mathrm{~kg} \cdot \mathrm{m}^{-2}$. In addition, a rigorous comparison would require a reduction of the value of Durrieu de Madron et al. (2005) in order to account for the total distance between doors instead of the width scraped by doors and groundropes.

A certain confusion can be noted in literature regarding the provided unit of trawling-induced erosion flux. For instance, Durrieu de Madron et al. (2005) expressed it in $\mathrm{kg} \cdot \mathrm{m}^{-2} \cdot \mathrm{s}^{-1}$, while in Dounas et al. (2007) the same flux value is reported in $\mathrm{kg} \cdot \mathrm{m}^{-2}$. Actually, the trawling-induced resuspension can be 
expressed as a mass of sediment either per unit area (then the width of the concerned surface becomes important), or per unit of track length. Trying to express it per unit time requires the insertion of the trawling speed, which is not relevant, nor necessary. In addition, the multiplication of such an eroded mass (per unit trawled length) by the fishing effort, for instance expressed as trawling length per unit area and unit time, leads straightforwardly to an erosion flux, in eroded mass per unit area and unit time (for instance in $\mathrm{kg} \cdot \mathrm{m}^{-2} \cdot \mathrm{s}^{-1}$ ). This is the type of information we recommend to use, as it enables the comparison with erosion fluxes due to the natural action of waves and currents in the same area. In addition, when the erosion rate is reported in $\mathrm{kg} \cdot \mathrm{m}^{-2}$ of trawled area, the width where it applies has to be specified. The order of magnitude of the resulting "fluxes" is not the same, so that attention should be paid when dealing with such data, especially when comparing literature data.

\subsection{Comparison between trawling-induced and natural erosion}

Combining the experimental trawling-induced erosion rate with fishing effort data over the GV provided an estimate of the time and space distribution of the anthropic resuspension. These anthropic erosion fluxes were compared to natural ones (i.e. waves and current action) after averaging at the monthly, seasonal, and annual time scales and over given bathymetric ranges.

Results show that bottom trawling can punctually become the dominant source of resuspension on the most intensively trawled part (e.g. between 90 and $120 \mathrm{~m}$ depth) of the GV during the high season of fishing (i.e. late spring/summer). The trawling-induced erosion dynamics seems to be regular from one year to the next given that fluxes deduced from fishing effort data of 2008, 2009 or monthly averaged over the 2005-2013 period remain similar. Thus, the significant and possible dominant contribution of trawling to resuspension, during the high season of fishing, depends on the inter-annual variability of natural forcing action. In winter, it clearly appears that averaged trawling-induced erosion fluxes are 2 to 3 orders of magnitude lower than natural ones, the latter controlling the annual erosion dynamics over the entire GV. However, the trawling-induced contribution to erosion may locally exceed a few per cents, especially in the northern part near Penmarc'h where the mud content is generally high (more than 50\%). It can be noticed that the more intensively trawled areas correspond to muddier sediments, so that the local erosion of fine sediments is all the more enhanced. Regarding the potential trawling influence outside the GV, it would be probably significant over zones with higher mud content due to higher penetration of trawl in the seabed. These muddy areas are not so much extended but constitute concentrated patches as the West and South Gironde mud fields in front of the mouth of the Gironde estuary (e.g. Bouysse et al. 1986). Along the coast and behind islands, muddy sediments are encountered in bays sheltered from long oceanic waves. But in these shallow areas, muddy sediments are likely to be eroded by wind-induced waves that may mask the anthropic effects.

Bourillet et al. (2006) had already proposed a similar evaluation of both natural- and anthropicinduced resuspension over the GV area. They found that fishing activities contributed as 10 to $30 \%$ of

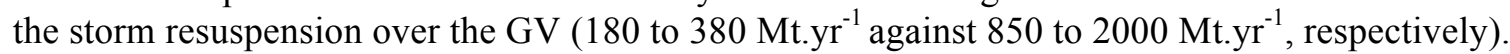

The lower contribution deduced from our study is partly due to differences in natural erosion evaluations, and partly to the trawling-induced resuspension rate.

Regarding the trawling impact, we estimate that the total resuspended mass of fine material over the 90-120 m bathymetric range of the GV area would be $1.5 \mathrm{Mt}_{\mathrm{yr}}^{-1}$ (against $180{\mathrm{Mt} . \mathrm{yr}^{-1}}^{-1}$ in Bourillet et al. 2006). Such a difference can be explained by different hypotheses regarding the gears penetration: Bourillet et al. (2006) considered a significant penetration of groundropes and sweeps (Fig. 5) leading to a remobilization 13 times larger per trawl, clearly overestimated when compared to our observations. Assuming even larger penetration depths (e.g. $15 \mathrm{~cm}$ for doors, $5 \mathrm{~cm}$ for chains) according to Løkkeborg (2005), Leynaud (2007) re-evaluated the contribution of trawling resuspension at $50 \%$. In addition, fishing effort data used by Bourillet et al. (2006) and Leynaud (2007) were less comprehensive and less accurate than present day VMS data.

On the other hand, wave-induced resuspension is computed under different assumptions leading to a total of $850 \mathrm{Mt} . \mathrm{yr}^{-1}$ in Bourillet et al. (2006), much more than our estimates over the same area (158 and $207 \mathrm{Mt}$ for 2008 and 2009 respectively). Bourillet et al. (2006) crudely estimated the naturalinduced resuspension fluxes by considering the occurrence of three classes of storms: extreme events 
(erosion fluxes of $10^{-3} \mathrm{~kg} \cdot \mathrm{m}^{-2} \cdot \mathrm{s}^{-1}$ occurring $0.3 \%$ of the year), intense ones (erosion fluxes of $6.10^{-4}$ $\mathrm{kg} \cdot \mathrm{m}^{-2} \cdot \mathrm{s}^{-1}$ occurring $1 \%$ of the year), and moderate ones (erosion fluxes of $2.10^{-4} \mathrm{~kg} \cdot \mathrm{m}^{-2} \cdot \mathrm{s}^{-1}$ occurring $3.5 \%$ of the year). Our natural resuspension assessment involves the actual history of wave forcing along two years and its spatial distribution using a validated new generation wave model, so that the new estimate seems more reliable.

It should be reminded that the computation of wave and current induced resuspension is strongly sensitive to the erosion law and to the bottom shear stress assessment. The former involves three parameters $\left(E_{0}, \tau_{c r}\right.$, and $n$ in Eq. 5) among which the erosion constant $\left(E_{0}\right)$ has a large weight because of the linearity of Eq. (5) regarding $E_{0}$. According to the literature, $E_{0}$ can be reasonably set to $10^{-4}$ or $10^{-6} \mathrm{~kg} \cdot \mathrm{m}^{-2} \cdot \mathrm{s}^{-1}$ instead of $10^{-5} \mathrm{~kg} \cdot \mathrm{m}^{-2} \cdot \mathrm{s}^{-1}$, as discussed in section 4.1 . The incidence on natural erosion flux and finally on the ratio between anthropic and natural effects is straightforward and is partly illustrated on Fig. 16. In the same way, the critical shear stress $\tau_{c r}$ can influence the integrated erosion flux. Dealing with muddy sands, the Shields critical shear stress validated for pure fine sands could reasonably be multiplied by a factor 2 (i.e. $\tau_{c r}=0.3 \mathrm{~N} . \mathrm{m}^{-2}$; Jacobs et al. 2011). It would limit natural erosion along the year, especially during summer months when the actual bed shear stress is often close to the critical value. This reduction of the natural forcing effect would lead to an increase of the trawling contribution. The impact of the exponent $n$ in Eq. (5) is lower as usual values remain between 1 and 1.6.

Last but not the least, the computation of the actual shear stress is dependent on the roughness length. Some ambiguity concerning the type of roughness (skin or form related) involved in wave-induced shear stress modelling (Appendix 2, Eqs. 2.1 and 2.2; Soulsby et al. 1993) allows significant variations of $\tau$.

Despite remaining uncertainties, the new computation has permitted to provide a more accurate spatiotemporal distribution of natural forcing. It has allowed to better quantify the trawling-induced erosion dynamics by estimating accurately the penetration of the different trawl constituents in the seabed. The use of a 3D sediment transport model, validated in terms of resuspension and turbidity, will enable to limit uncertainties concerning the results sensitivity to the setting of natural erosion and thus to clarify the relative natural and anthropic contributions to erosion.

These results related to the Bay of Biscay can be compared with published results in other sites and are qualitatively in agreement. In the Gulf of Lions (Mediterranean sea), Ferré et al. (2008) used a sediment dynamics model to assess the relative natural and trawling contributions to resuspension fluxes. They concluded that in summer in the outer shelf (i.e. between 80 and $130 \mathrm{~m}$ depth), trawlinginduced erosion fluxes could significantly exceed wave- and current-induced fluxes by a factor ranged between 1.5 and 3 , while at the annual scale the natural resuspension fluxes remained dominant. The maximum annually-integrated trawling-induced resuspension flux was reached in the $90-110 \mathrm{~m}$ bathymetric range, and represented almost $10 \%$ of the natural flux. The larger relative contribution of trawling these authors obtained in the Gulf of Lions may be due to a lower wave action, compared to the energetic wave climate of the Bay of Biscay, and to a possible muddier seabed, less resistant to penetration. At the scale of the Gulf of Lions shelf, Ferré et al. (2008) mentioned that the amount of sediment resuspended by waves and currents exceeds by three to four orders of magnitude the trawling-induced one.

In the Middle Atlantic Bight, Churchill's precursor modelling work (1989) concluded that trawlinginduced sediment resuspension significantly contributes to the suspended sediment load where the influence of natural forcing significantly declines, i.e. on the outer shelf: average trawling-induced sediment load during the high season can there exceed the natural-induced one by a factor 6 to 20 . In the middle shelf region (water depth $<100 \mathrm{~m}$ ), Churchill's results show that trawling becomes significant but not dominant from late spring to autumn, and that the yearly-averaged suspended sediment mass over the Mid-Atlantic Bight continental shelf is dominated by natural resuspension during the stormy season. 


\section{$\underline{5.5 \text { Possible consequences on sediment fluxes }}$}

The fate of resuspended particles remains an important question not addressed in this paper. Some studies conducted on other study sites highlighted a significant contribution of bottom trawling to the off-shelf export of sediment. It is the case of Ferré et al. (2008) in the Gulf of Lions who estimated that trawling activities could contribute between a few and $20 \%$ of the annual shelf-to-slope export of suspended sediment. More recently, Oberle et al. (2015a) estimated that $65 \%$ of resuspended sediments by bottom trawling on the NW Iberian shelf $\left(8.78{\mathrm{Mt} . y r^{-1}}^{-1}\right)$ were exported off-shelf, which represents a six-fold increase regarding natural off-shelf sediment transport (1.46 Mt.yr $\left.{ }^{-1}\right)$.

Concerning the fate of the fine particles resuspended in the Bay of Biscay, Castaing et al. (1999) showed the existence of a westerly bottom circulation at $47^{\circ} \mathrm{N}$ that could contribute to the export of sediments beyond the continental slope. In that case, these particles are definitely lost. On the opposite, Pinot (1974) suggested that a potential transport of these particles toward the coast could lead to a possible increase of siltation in coastal muddy areas. The specific period of trawling-induced resuspension, mainly in summer and out of phase with winter wave-induced resuspension, is likely to generate other sediment paths, different from the ones related to natural forcing, because of seasonal changes of bottom circulation in the Bay of Biscay. Indeed, such seasonal variations have been recently described by Charria et al. (2013) and Le Boyer et al. (2013), which motivates a regional study of sediment budget and fluxes in the whole area. Then it should become possible to confirm whether trawling-induced resuspension can be neglected to describe these fluxes or should be taken into account because of specific flow patterns during high fishing season.

\section{Conclusions}

This study aimed at using in situ data in order to accurately quantify the impacts of bottom trawling on resuspension, suspended matter dynamics in the water column, and seabed micro-topography disturbances in the Bay of Biscay. Two zones of the "Grande-Vasière" characterized by contrasting seabed facies and fishing efforts were chosen to quantify these processes.

Turbid plumes generated behind a "classical" trawl configuration have been described and appear to be mainly due to the doors scraping the seabed. SSC values measured within the plume range from 100 to $200 \mathrm{mg} . \mathrm{l}^{-1}$ in the immediate vicinity of the trawl, and rapidly decrease in the trawl wake. Mean $S S C$ values in the turbid plume are around $70 \mathrm{mg} \cdot \mathrm{l}^{-1}$. Beyond $800 \mathrm{~m}$ behind the trawl doors, the plume's signature is not captured any more, probably because of the combined action of settling and advection processes. The use of relatively small gears explains that the turbid plume is confined in the first $3 \mathrm{~m}$ above the seabed. An "alternative" trawl configuration using "Jumper" doors, which have an intermittent contact with the seabed, was tested on the same zones. Measurements just behind the trawl exhibit SSC values 10 times lower than behind the "classical" configuration and SSC values of a few mg. $1^{-1}$ are measured further behind the trawl. These results prove that this "alternative" configuration is effectively less damaging regarding the seabed.

Bioturbation seems to largely contribute to the homogenisation of the surficial sediment (first $25 \mathrm{~cm}$ ). The upper 3 to 4 centimetres nevertheless exhibit vertical gradients in grain size and mud content. The moderately trawled zone exhibits an upward increase of the grain size-related parameters standard deviation. In the intensively trawled zone, more pronounced trends are observed with upward increases of $d_{10}(+450 \%)$ and $d_{50}(+17 \%)$, and a decrease in mud content $(-41 \%)$. These results suggest the potential role of bottom trawling in fine fraction winnowing of the seabed. These conclusions are coherent with the long-term decrease in mud content (around 30\%) which has been observed in the intensively trawled area between 1967 and 2014 whereas no significant change occurred in the moderately trawled area over the same period. Given that relative differences between the two zones cannot be explained by natural forcing gradients over this period (i.e. wave, current, wind, river discharge), this trend could be related to a long-term effect induced by bottom trawling.

The trawl doors leave $4-5 \mathrm{~cm}$ deep and about $20 \mathrm{~cm}$ wide asymmetric tracks in the seabed whereas other constituents (i.e. mainly groundropes) only have a flattening action on the seabed. Processing the 
door tracks' cross-sections provided an estimate of the trawl-induced erosion rate of around $0.13 \mathrm{~kg} . \mathrm{m}^{-}$

${ }^{2}$ consistent with other results in the literature.

This trawling-induced resuspension rate was combined with fishing effort data in order to estimate the overall trawling-induced resuspension fluxes in the GV and compare it to natural erosion fluxes. Natural fluxes were obtained using a period-averaged wave model, a 3D circulation model and a classic erosion law from the literature. Using modelled boundary conditions and actual meteorological forcing, a realistic simulation of the whole Bay of Biscay currents and waves was carried out over two years and was used in order to assess the magnitude of natural resuspension. Results suggest that bottom trawling can become the main factor of resuspension in intensively trawled zones of the GV during calm periods (i.e. high season of fishing during summer period). However, the annual mass of sediment eroded by bottom trawling only represents around $1 \%$ of total mass resuspended by winter storms over the most intensively trawled area of the GV (i.e. between 90 and $120 \mathrm{~m}$ depth). The ratio between natural and anthropogenic resuspensions remains dependent on the erosion parameters selected for the natural flux computation, and the setting up of a validated full 3D model including effects of trawling and respecting different bottom circulation schemes in winter when storm waves occur and in summer when fishing effort is maximum should allow a final conclusion on the trawling contribution to sediment fluxes and balance in the Bay of Biscay.

\section{Acknowledgements}

This study was supported by the SHOM (Service Hydrographique et Océanographique de la Marine) and IFREMER (Institut Français de Recherche pour l'Exploitation de la Mer). Sea trials were funded by the BENTHIS European project (grant agreement $n^{\circ} 312088$ ). The authors would like to thank Matthias JACQUET and David LE BERRE from IFREMER for technical support as well as the crews of the N/O Thalia and the F/V Côte d'Ambre for their assistance during all the campaigns. They also thank François Le Loc'h who supplied surficial mud content data over the 2000-2002 period. Jumper doors have been invented by Benoit Vincent in 2008 with the co-funding of the Région Bretagne, France Fillière Pêche and IFREMER (between 2013 and 2015), as well as the Morgère company that provided support for the development. Lastly, the two anonymous reviewers are deeply thanked for their comments and suggestions that greatly improved the manuscript.

\section{Appendix 1 Backscatter index provided by ADCP}

Tessier et al. (2008b) proposed a processing method for the RDI ADCP $1200 \mathrm{kHz}$ used in this study. All the following coefficients and hypotheses are thus directly extracted from Tessier et al. (2008b). As deduced from the sonar equation (Urick 1975; Lurton 2002), they expressed the backscatter index $B I$ according to the relation:

$B I=R L-S L+T L_{g e o}+T L_{w s}-C_{g e o}$

where $R L$ is the received level in $\mathrm{dB} . \mu \mathrm{Pa}^{-1}$ and is expressed as:

$R L=B+K C .\left(E C-E C_{0}\right)$

where $B$ and $E C_{0}$ are internal transducer noises respectively set at $70 \mathrm{~dB}$ and 46 counts, $K C$ is a $\mathrm{dB} /$ count conversion coefficient, fixed at 0.423 , and $E C$ is the echo received signal in count. $S L$ corresponds to the emitted level and is set to $217 \mathrm{~dB} . \mu \mathrm{Pa}^{-1} . T L_{g e o}$ and $T L_{w s}$ are terms linked to the transmission loss along the beam path (in $\mathrm{dB}$ ). $T L_{\text {geo }}$ is the geometrical attenuation for the spherical spreading and is expressed as: 
where $R$ is the distance from the transducer and $\psi$ is the near field correction. $T L_{w s}$ corresponds to the signal attenuation induced by the water and the particles and is expressed as:

$T L_{w s}=2 \cdot\left(\alpha_{w}+\alpha_{S}\right) \cdot R$

where $\alpha_{w}$ is the water attenuation coefficient set to $0.5316 \mathrm{~dB} \cdot \mathrm{m}^{-1}$ according to the model of Francois and Garrison (1982a,b). When the suspended particulate matter concentrations are generally inferior to $200 \mathrm{mg} .1^{-1}$, the signal attenuation induced by the particles can be neglected $\left(\alpha_{S}=0\right)$.

At last, $C_{\text {geo }}$ corresponds to a geometric correction that accounts for the expansion of the backscattering volume with the increasing distance $R$ from the source. It is defined as:

$C_{g e o}=10 \cdot \log _{10}\left(\pi \cdot\left(\frac{\phi}{2}\right)^{2} \cdot R^{2} \cdot L\right)$

where $\phi$ is the equivalent opening of the beam and $L$ refers to the half-height cell.

\section{Appendix 2 Computation of the bed shear stress under natural forcing}

\section{Computation of the wave shear stress}

Wave-induced bottom shear stresses have been computed with a wave hindcast database built with the WW3 wave model (Boudière et al. 2013) that provides parameters such as bottom amplitude displacement $(A)$, bottom orbital velocities $\left(U_{b}\right)$, and the direction of wave propagation. The WW3 code is a phase-averaged wave model that resolves the random phase spectral action density balance equation for a spectrum of wave numbers and directions: in the present application, 24 directions and 32 frequencies were accounted for. The realistic and validated configuration proposed by Boudière et al. (2013) includes all the continental shelf of the Bay of Biscay, using an unstructured grid. The horizontal resolution of the computational grid varies in our case from $200 \mathrm{~m}$ (nearshore) to $10 \mathrm{~km}$ (open sea). According to Jonsson (1966) formulation, the wave-induced shear stress $\tau_{w}$ is computed as:

$\tau_{w}=\frac{1}{2} f_{w} \rho U_{b}^{2}$

where $\rho$ is the water density and $f_{w}$ refers to the wave-induced friction factor. This factor is computed according to the Soulsby et al. (1993) formulation:

$f_{w}=1.39\left(\frac{A}{z_{0}}\right)^{-0.52}$

where the bed roughness length $z_{0}$ is equal to $5 \times 10^{-4} \mathrm{~m}$.

\section{Computation of the current shear stress}

The current-induced bottom shear stress estimation is based on the tridimensional hydrodynamic model MARS3D (Lazure and Dumas 2008) which runs on a realistic configuration validated at the regional scale of the Bay of Biscay. This model resolves the Navier-Stokes equations with the 
classical Boussinesq and hydrostatic hypotheses on Cartesian grid. Regarding the mesh, the horizontal resolution is equal to $2.5 \mathrm{~km}$ and the vertical discretisation is characterised by 40 generalised sigma levels. The bed shear stress induced by currents is obtained through the relationship:

$\tau_{c}=\rho u_{*}^{2}$

where the friction velocity $u *$ is computed as:

$u_{*}=0.4 u_{1} / \ln \left(\frac{z_{1}}{z_{0}}\right)$

where $\rho$ is the water density, $u_{l}$ is the computed velocity at the elevation $z_{l}$ which corresponds to half the near-bottom cell thickness, and $z_{0}$ is the bottom sediment roughness length set to a constant value of $5 \times 10^{-4} \mathrm{~m}$.

\section{Computation of the total bottom shear stress}

The non-linear interaction between waves and currents is accounted for by computing the total bottom shear stress according to the formulation from Soulsby (1997):

$\tau=\left[\left(\tau_{m}+\tau_{w}|\cos \phi|\right)^{2}+\left(\tau_{w} \sin \phi\right)^{2}\right]^{1 / 2}$

where $\phi$ is the angle between the current and the wave propagation directions and $\tau_{m}$ represents the wave-averaged bed shear stress. $\tau_{m}$ is computed from the current- and wave-induced bed shear stresses $\tau_{c}$ and $\tau_{w}$ which correspond to the bed shear-stresses due to the current alone and to the wave alone, respectively:

$\tau_{m}=\tau_{c}\left[1+1.2\left(\frac{\tau_{w}}{\tau_{c}+\tau_{w}}\right)^{3.2}\right]$

The expression of $\tau$ is deduced from a vector addition of $\tau_{m}$ and $\tau_{w}$.

\section{References}

Amos CL, Daborn GR, Christian HA, et al (1992) In situ erosion measurements on fine-grained sediments from the Bay of Fundy. Marine Geology 108:175-196.

Amos CL, Feeney T, Sutherland TF, Luternauer JL (1997) The stability of fine-grained sediments from the Fraser River Delta. Estuarine, Coastal and Shelf Science 45:507-524.

Barthe X, Castaing P (1989) Etude théorique de l'action des courants de marée et des houles sur les sédiments du plateau continental du Golfe de Gascogne. Oceanologica Acta 12:325-334.

Beach RA, Sternberg RW (1988) Suspended sediment transport in the surf zone: response to crossshore infragravity motion. Marine Geology 80:61-79.

Boudière E, Maisondieu C, Ardhuin F, et al (2013) A suitable metocean hindcast database for the design of Marine energy converters. International Journal of Marine Energy 3-4:e40-e52. doi: 10.1016/j.ijome.2013.11.010.

Bourillet J-F, Dubrulle C, Goubert E, et al (2005) La Grande Vasière: architecture, mise en place et estimation des facteurs de son évolution. In: Colloque Défi Golfe de Gascogne. Ifremer, Brest. pp $22-24$. 
Bourillet J-F, Jouanneau J-M, Macher C, et al (2006) “ La Grande Vasière” mid-shelf mud belt: Holocene sedimentary structure, natural and anthropogenic impacts. In: $\mathrm{X}$ International Symposium on Oceanography of the Bay of Biscay, April 19-21 2006. Vigo, Galicia. Spain.

Bouysse P, Lesueur P, Klingebiel A (1986) Carte des sédiments superficiels du plateau continental du Golfe de Gascogne: partie septentrionale au 1/500.000. co-éditée par BRGM et IFREMER. http://sextant.ifremer.fr/record/ea0b61b0-71c6-11dc-b1e4-000086f6a62e/.

Bradshaw C, Tjensvoll I, Sköld M, et al (2012) Bottom trawling resuspends sediment and releases bioavailable contaminants in a polluted fjord. Environmental Pollution 170:232-241. doi: 10.1016/j.envpol.2012.06.019.

Brown CJ, Cooper KM, Meadows WJ, et al (2002) Small-scale mapping of sea-bed assemblages in the eastern English Channel using sidescan sonar and remote sampling techniques. Estuarine, Coastal and Shelf Science 54:263-278. doi: doi:10.1006/ecss.2001.0841.

Brown EJ, Finney B, Dommisse M, Hills S (2005) Effects of commercial otter trawling on the physical environment of the southeastern Bering Sea. Continental Shelf Research 25:1281-1301. doi: 10.1016/j.csr.2004.12.005.

Castaing P (1981) Le transfert à l'océan des suspensions estuariennes: cas de la Gironde. Ph. D. Thesis. University of Bordeaux, France, p 530.

Castaing P, Froidefond JM, Lazure P, et al (1999) Relationship between hydrology and seasonal distribution of suspended sediments on the continental shelf of the Bay of Biscay. Deep Sea Research Part II: Topical Studies in Oceanography 46:1979-2001.

Castaing P, Jouanneau JM (1987) Les apports sédimentaires actuels d'origine continentale aux océans. Bull IGBA 41:53-60.

Charria G, Lazure P, Le Cann B, et al (2013) Surface layer circulation derived from Lagrangian drifters in the Bay of Biscay. Journal of Marine Systems 109-110:S60-S76.

Chittenden Jr ME, Van Engel WA (1972) Effect of a tickler chain and tow duration on trawl catches of the blue crab, Callinectes sapidus. Transactions of the American Fisheries Society 101:732-734.

Churchill JH (1989) The effect of commercial trawling on sediment resuspension and transport over the Middle Atlantic Bight continental shelf. Continental Shelf Research 9:841-865. doi: 10.1016/0278-4343(89)90016-2.

Cole HA (1971) HEAVY TICKLER CHAIN-RIGHT OR WRONG. World Fishing 20:8.

Cornou A-S, Quinio-Scavinner M, Delaunay D, et al (2015) Observations à bord des navires de pêche professionnelle. Bilan de l'échantillonnage 2014. Technical Report Ifremer. http://doi.org/10.13155/39722.

Darboux F, Huang C (2003) An instantaneous-profile laser scanner to measure soil surface microtopography. Soil Science Society of America Journal 67:92-99.

De Groot SJ (1984) The impact of bottom trawling on benthic fauna of the North Sea. Ocean Management 9:177-190. doi: 10.1016/0302-184X(84)90002-7.

Dellapenna TM, Allison MA, Gill GA, et al (2006) The impact of shrimp trawling and associated sediment resuspension in mud dominated, shallow estuaries. Estuarine, Coastal and Shelf Science 69:519-530. doi: 10.1016/j.ecss.2006.04.024.

Dounas C, Davies I, Triantafyllou G, et al (2007) Large-scale impacts of bottom trawling on shelf primary productivity. Continental Shelf Research 27:2198-2210.

Draye R (2015) Caractérisation à haute résolution de la structure physique et de l'organisation biologique des fonds marins par traitement d'images à partir d'un micro-tropographe laser. Rapport de Master 2. Université Paul Sabatier Toulouse III, Ifremer EMH Nantes (France).

Dubrulle C, Jouanneau JM, Lesueur P, et al (2007) Nature and rates of fine-sedimentation on a midshelf: "La Grande Vasière" (Bay of Biscay, France). Continental Shelf Research 27:2099-2115.

Durrieu de Madron X, Ferré B, Le Corre G, et al (2005) Trawling-induced resuspension and dispersal of muddy sediments and dissolved elements in the Gulf of Lion (NW Mediterranean). Continental Shelf Research 25:2387-2409. doi: 10.1016/j.csr.2005.08.002.

Eigaard OR, Bastardie F, Breen M, et al (2015) Estimating seabed pressure from demersal trawls, seines, and dredges based on gear design and dimensions. ICES Journal of Marine Science 73:i27-i43. https://doi.org/10.1093/icesjms/fsv099.

Ferré B, Durrieu de Madron X, Estournel C, et al (2008) Impact of natural (waves and currents) and anthropogenic (trawl) resuspension on the export of particulate matter to the open ocean: 
Application to the Gulf of Lion (NW Mediterranean). Continental Shelf Research 28:2071-2091. doi: 10.1016/j.csr.2008.02.002.

Folliot B (2004) La Grande Vasière: étude sédimentologique de deux secteurs septentrionaux. Mémoire de DEA Dynamique et environnements sédimentaires de Lille-Caen-Rouen, France, p 39.

Francois RE, Garrison GR (1982a) Sound absorption based on ocean measurements. Part II: Boric acid contribution and equation for total absorption. The Journal of the Acoustical Society of America 72:1879-1890.

Francois RE, Garrison GR (1982b) Sound absorption based on ocean measurements: Part I: Pure water and magnesium sulfate contributions. The Journal of the Acoustical Society of America 72:896907.

Gartner JW (2004) Estimating suspended solids concentrations from backscatter intensity measured by acoustic Doppler current profiler in San Francisco Bay, California. Marine Geology 211:169187.

Gerritsen HD, Minto C, Lordan C (2013) How much of the seabed is impacted by mobile fishing gear? Absolute estimates from Vessel Monitoring System (VMS) point data. ICES Journal of Marine Science 70:523-531.

Gerritsen H, Lordan C (2010) Integrating vessel monitoring systems (VMS) data with daily catch data from logbooks to explore the spatial distribution of catch and effort at high resolution. ICES Journal of Marine Science 68:245-252.

Gilkinson K, King EL, Li MZ, et al (2015) Processes of physical change to the seabed and bivalve recruitment over a 10-year period following experimental hydraulic clam dredging on Banquereau, Scotian Shelf. Continental Shelf Research 92:72-86. doi: 10.1016/j.csr.2014.11.006.

Graham M (1955) Effect of trawling on animals of the sea bed. Deep Sea Research 3:1-6.

Hall SJ (1999) The effects of fishing on marine ecosystems and communities. Blackwell, Oxford.

Hintzen NT, Piet GJ, Brunel T (2010) Improved estimation of trawling tracks using cubic Hermite spline interpolation of position registration data. Fisheries Research 101:108-115.

Jacobs W, Le Hir P, Van Kesteren W, Cann P (2011) Erosion threshold of sand-mud mixtures. Continental Shelf Research 31:S14-S25.

Jennings S, Kaiser M, Reynolds JD (2009) Marine fisheries ecology. John Wiley \& Sons, Oxford.

Jones JB (1992) Environmental impact of trawling on the seabed: a review. New Zealand Journal of Marine and Freshwater Research 26:59-67.

Jonsson IG (1966) Wave boundary layers and friction factors. In: Proceedings of 10th International Conference on Coastal Engineering. American Society of Civil Engineers, New York, pp 127148.

Jouanneau JM, Weber O, Cremer M, Castaing P (1999) Fine-grained sediment budget on the continental margin of the Bay of Biscay. Deep Sea Research Part II: Topical Studies in Oceanography 46:2205-2220.

Kaiser MJ, Collie JS, Hall SJ, et al (2002) Modification of marine habitats by trawling activities: prognosis and solutions. Fish and Fisheries 3:114-136.

Krost P, Bernhard M, Werner F, Hukriede W (1989) Otter trawl tracks in Kiel Bay (Western Baltic) mapped by side-scan sonar. Meeresforschung 32:344-353.

Lambert GI, Jennings S, Hiddink JG, et al (2012) Implications of using alternative methods of vessel monitoring system (VMS) data analysis to describe fishing activities and impacts. ICES Journal of Marine Science 69:682-693.

Lazure P, Dumas F (2008) An external-internal mode coupling for a 3D hydrodynamical model for applications at regional scale (MARS). Advances in Water Resources 31:233-250.

Lazure P, Jégou A-M (1998) 3D modelling of seasonal evolution of Loire and Gironde plumes on Biscay Bay continental shelf. Oceanologica acta 21:165-177.

Le Boyer A, Charria G, Le Cann B, et al (2013) Circulation on the shelf and the upper slope of the Bay of Biscay. Continental Shelf Research 55:97-107.

Lee J, South AB, Jennings S (2010) Developing reliable, repeatable, and accessible methods to provide high-resolution estimates of fishing-effort distributions from vessel monitoring system (VMS) data. ICES Journal of Marine Science 67:1260-1271. 
Le Loc'h F (2004) Structure, fonctionnement, évolution des communautés benthiques des fonds meubles exploités du plateau continental Nord Gascogne. Ph. D. Thesis. University of Western Brittany, Brest, France, p 378.

Leynaud D (2007) Evolution sédimentologique de la Grande Vasière (GV). Rapport d'activité, LEMAR-IUEM (France).

Linnane A, Ball B, Munday B, et al (2000) A review of potential techniques to reduce the environmental impact of demersal trawls. Irish Fisheries Investigations 7:1-39.

Løkkeborg S (2005) Impacts of trawling and scallop dredging on benthic habitats and communities. FAO, Rome.

Lurton X (2002) An introduction to underwater acoustics: principles and applications. Springer-Verlag, Berlin.

Main J, Sangster GI (1979) A Study of Bottom Trawling Gear on Both Sand and Hardground. Scottish fisheries research report 14:1-15.

Main J, Sangster GI (1981) A study of the sand clouds produced by trawl boards and their possible effect on fish capture. Scottish fisheries research report 20:1-20.

Main J, Sangster GI (1983) Fish reactions to trawl gear: A study comparing light and heavy ground gear. Scottish fisheries research report 27:1-17.

Manning AJ, Dyer KR (1999) A laboratory examination of floc characteristics with regard to turbulent shearing. Marine Geology 160:147-170.

Martín J, Puig P, Palanques A, Giamportone A (2014) Commercial bottom trawling as a driver of sediment dynamics and deep seascape evolution in the Anthropocene. Anthropocene 7:1-15.

Mayer LM, Schick DF, Findlay RH, Rice DL (1991) Effects of commercial dragging on sedimentary organic matter. Marine Environmental Research 31:249-261. doi: 10.1016/0141-1136(91)90015Z.

McCave IN (1972) Transport and escape of fine-grained sediment from shelf areas. In: Swift DJP, Duane B, Pilkey OH (Eds.) Shelf Sediment Transport: Process and Pattern. Hutchinson and Ross, Stroudsburg, PA, Dowden, pp 225-248.

Mesnil B (2008) Public-aided crises in the French fishing sector. Ocean \& coastal management 51:689-700.

Mulder HP, Udink C (1991) Modelling of cohesive sediment transport. A case study: the western Scheldt estuary. In: Edge, B.L. (Ed.), Proceedings of the 22nd International Conference on Coastal Engineering. American Society of Civil Engineers, pp 3012-3023.

Oberle FK, Storlazzi CD, Hanebuth TJ (2015a) What a drag: Quantifying the global impact of chronic bottom trawling on continental shelf sediment. Journal of Marine Systems. doi: http://dx.doi.org/10.1016/j.jmarsys.2015.12.007.

Oberle FK, Swarzenski PW, Reddy CM, et al (2015b) Deciphering the lithological consequences of bottom trawling to sedimentary habitats on the shelf. Journal of Marine Systems. doi: http://dx.doi.org/10.1016/j.jmarsys.2015.12.008.

Olsen C fR, Cutshall NH, Larsen IL (1982) Pollutant—particle associations and dynamics in coastal marine environments: a review. Marine Chemistry 11:501-533.

O'Neill FG, Summerbell K (2011) The mobilisation of sediment by demersal otter trawls. Marine pollution bulletin 62:1088-1097.

O’Neill FG, Summerbell K, Breen M (2009) An underwater laser stripe seabed profiler to measure the physical impact of towed gear components on the seabed. Fisheries Research 99:234-238.

Palanques A, Guillén J, Puig P (2001) Impact of bottom trawling on water turbidity and muddy sediment of an unfished continental shelf. Limnology and Oceanography 46:1100-1110.

Palanques A, Puig P, Guillén J, et al (2014) Effects of bottom trawling on the Ebro continental shelf sedimentary system (NW Mediterranean). Continental Shelf Research 72:83-98. doi: 10.1016/j.csr.2013.10.008.

Pilskaln CH, Churchill JH, Mayer LM (1998) Resuspension of sediment by bottom trawling in the Gulf of Maine and potential geochemical consequences. Conservation Biology 12:1223-1229.

Pinot J-P (1974) Le précontinent Breton: entre Penmarc'h, Belle-Ile et l'escarpement continental, étude géomorphologique. Impram Lannion, France.

Pinot JP (1976) Géomorphologie de la plateforme continentale sud-armoricaine. Journal de Recherche Océanographique, Paris 1:49-56. 
Planque B, Beillois P, Jégou A-M, et al (2003) Large-scale hydroclimatic variability in the Bay of Biscay: the 1990s in the context of interdecadal changes. ICES Marine Science Symposia 219:61-70.

Puig P, Canals M, Company JB, et al (2012) Ploughing the deep sea floor. Nature 489:286-289.

Pusceddu A, Bianchelli S, Martín J, et al (2014) Chronic and intensive bottom trawling impairs deepsea biodiversity and ecosystem functioning. Proceedings of the National Academy of Sciences 111:8861-8866.

Rijnsdorp AD, Buys AM, Storbeck F, Visser EG (1998) Micro-scale distribution of beam trawl effort in the southern North Sea between 1993 and 1996 in relation to the trawling frequency of the sea bed and the impact on benthic organisms. ICES Journal of Marine Science 55:403-419.

Schoellhamer DH (1996) Anthropogenic Sediment Resuspension Mechanisms in a Shallow Microtidal Estuary. Estuarine, Coastal and Shelf Science 43:533-548. doi: 10.1006/ecss.1996.0086.

Schubel JR, Carter HH, Wise WM (1979) Shrimping as a source of suspended sediment in Corpus Christi Bay (Texas). Estuaries 2:201-203.

Schwinghamer P, Guigne JY, Siu WC (1996) Quantifying the impact of trawling on benthic habitat structure using high resolution acoustics and chaos theory. Canadian Journal of Fisheries and Aquatic Sciences 53:288-296.

Simpson AW, Watling L (2006) An investigation of the cumulative impacts of shrimp trawling on mud-bottom fishing grounds in the Gulf of Maine: effects on habitat and macrofaunal community structure. ICES Journal of Marine Science 63:1616-1630.

Skaar KL, Jørgensen T, Ulvestad BKH, Engås A (2011) Accuracy of VMS data from Norwegian demersal stern trawlers for estimating trawled areas in the Barents Sea. ICES Journal of Marine Science 68:1615-1620.

Soulsby R (1997) Dynamics of marine sands: a manual for practical applications. Thomas Telford, London.

Soulsby RL, Hamm L, Klopman G, et al (1993) Wave-current interaction within and outside the bottom boundary layer. Coastal engineering 21:41-69.

Syvitski JP, Vörösmarty CJ, Kettner AJ, Green P (2005) Impact of humans on the flux of terrestrial sediment to the global coastal ocean. Science 308:376-380.

Tessier C (2006) Caractérisation et dynamique des turbidités en zone côtière: l'exemple de la région marine Bretagne Sud. University of Bordeaux 1, France, p 300.

Tessier C, Le Hir P, Dumas F, Jourdin F (2008a) Modélisation des turbidités en Bretagne sud et validation par des mesures in situ. European Journal of Environmental and Civil Engineering 12:179-190.

Tessier C, Le Hir P, Lurton X, Castaing $\mathrm{P}$ (2008b) Estimation de la matière en suspension à partir de l'intensité rétrodiffusée des courantomètres acoustiques à effet Doppler (ADCP). Comptes Rendus Geoscience 340:57-67.

Urick RJ (1975) Principles of Underwater Sound, 2nd edn. McGraw Hill, New York.

Van Beek FA, Van Leeuwen PI, Rijnsdorp AD (1990) On the survival of plaice and sole discards in the otter-trawl and beam-trawl fisheries in the North Sea. Netherlands Journal of Sea Research 26:151-160.

Vanney J-R (1977) Géomorphologie de la marge continentale sud-armoricaine. Société d'édition d'enseignement supérieur, Paris.

Vincent B, Vacherot J-P, Dagorn M, et al (2015) Optimisation des panneaux Jumper-Rapport final.

Watling L, Norse EA (1998) Disturbance of the seabed by mobile fishing gear: a comparison to forest clearcutting. Conservation Biology 12:1180-1197.

Wheatcroft RA, Drake DE (2003) Post-depositional alteration and preservation of sedimentary event layers on continental margins, I. The role of episodic sedimentation. Marine Geology 199:123137.

Widdows J, Brinsley MD, Bowley N, Barrett C (1998) A benthic annular flume for in situ measurement of suspension feeding/biodeposition rates and erosion potential of intertidal cohesive sediments. Estuarine, Coastal and Shelf Science 46:27-38. 